\title{
Conformational Analysis of Glycosaminoglycans. III. Conformational Properties of Hyaluronic Acid and Sodium Hyaluronate
}

\author{
R. Potenzone, Jr. and A. J. Hopfinger* \\ Department of Macromolecular Science, Case Western Reserve University, \\ Cleveland, Ohio 44106, U.S.A.
}

(Received July 20, 1977)

\begin{abstract}
We present the results of our theoretical conformational analysis of hyaluronic acid (HA) and sodium hyaluronate. Empirical potential energy functions for steric, electrostatic, hydrogen bonding, torsional, and solvation energies were used to evaluate the conformational energy with the CAMSEQ Software System. A trisaccharide model of the HA polymer was employed. Three chemical states were studied: $\mathrm{HA}^{-}$, charged $\mathrm{HA}$ in the absence of a counter-ion, neutral $\mathrm{pH}$, and very low ionic strength; $\mathrm{HAH}$, uncharged, protonated $\mathrm{HA}$, low $\mathrm{pH} ; \mathrm{HA}^{-} \cdot \mathrm{Na}^{+}$, charged $\mathrm{HA}$ with sodium ion present, neutral $\mathrm{pH}$, and high ionic strength. Two sets of conformational energy data were collected. The first was generated by a series of sequential and random scans followed by gradient-search minimizations at each of the local minima. This was intended to give a general picture of the energy surface of each form of HA. The second data set consisted of 10,000 randomly generated conformations for each form. This was sufficient to account for the minima found in the first data set. The second set of energies was employed to estimate the partition function and corresponding chain dimensions for comparison with available hydrodynamic data. In addition, we compare and contrast our structural findings with the published crystal structures of HA.
\end{abstract}

KEY WORDS Hyaluronic Acid / Conformational Analysis / Glycosaminoglycans /

This is the third paper in a series dealing with the conformational properties of the acidic glycosaminoglycans (GAG). The results of extensive theoretical conformational analyses of hyaluronic acid (HA) and its sodium salt are reported. We have concerned ourselves with structural calculations of HA in order to understand its conformational behavior in solution. This will hopefully provide a basis for further structural studies focusing upon a molecular description of the GAG-protein interactions described in detail by Hopfinger. ${ }^{1}$

HA occurs naturally as a repeating disaccharide. The monomer consists of $\beta$-D $(1 \rightarrow 4)$ linked Dglucuronic acid and 2-amino-2-deoxy-D-glucose which are joined through a $\beta$-D $(1 \rightarrow 3)$ glycosidic linkage to form the polymer (Figure 1). There is

* Sloan Research Fellow, to whom reprint requests should be sent. one ionizable carboxyl group per disaccharide. Hyaluronic acid was first isolated in 1934 by Meyer and Palmer. ${ }^{2}$ It is found in various locations throughout the human body, e.g., vitreous humor, skin, umiblical cord, cartilage, and synovial fluid. Often HA is found in association with proteins and other glycosaminoglycans, but is believed to be the only GAG which is not covalently bound to protein. There is also evidence to suggest that HA is involved in water binding in tissues. $^{3}$ Because of these observations of biological function, HA has been the subject of many studies employing a variety of structural probes.

Early viscosity studies on HA isolated from vitreous humor, umbilical cord, and synovial fluid by Blix and Snellman ${ }^{4}$ showed a molecular weight of 200,000 to 500,000 and particle lengths of $4800 \AA$ to $10,000 \AA$. Several other molecular 


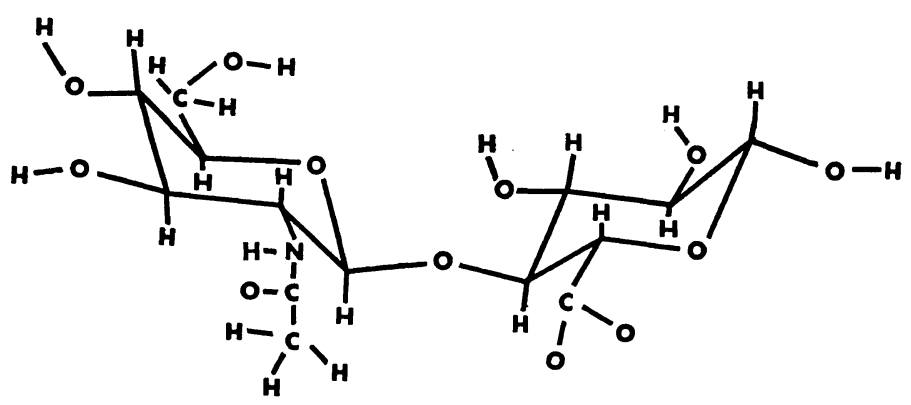

Figure 1. Chemical repeat unit of hyaluronic acid.

weight determinations have been reported and reviewed. $^{5-10}$ The values differ depending on source, preparation, and method of measurement. Molecular weights generally range from $10^{5}$ to $10^{6}$ and such techniques as light scattering, ${ }^{11-17}$ sedimentation and diffusion, ${ }^{14,17}$ ultracentrifugation, ${ }^{18,19}$ sedimentation and viscosity, ${ }^{20,21}$ osmometry, ${ }^{17,22}$ and streaming birefringence ${ }^{13}$ have been reported. The molecular shape of $\mathrm{HA}$ in solution under physiological $\mathrm{pH}$ and ionic strength, has been examined using the above (as well as several additional) techniques. Early detailed aqueous solution studies were reported by Ogston and Stanier. $^{23,24}$ They conclude that HA is a highly solvated random coil undergoing increasing interchain interaction with increasing concentration. These results are in general agreement with more recent work employing light scattering. ${ }^{14,15}$

The polyelectrolyte nature of HA along with the corresponding consequences on its conformation has also been extensively studied. The ionizable side group has a pK of 3.21. ${ }^{5}$ Ion binding studies ${ }^{25}$ suggest the sodium ion activities are higher than in other polyelectrolytes, in turn suggesting that only a few of the carboxyl groups seem to effectively bind $\mathrm{Na}^{+}$directly. This binding increases as the sodium concentration is raised.

Electrophoresis has been used to estimate that $14 \%$ of the charged sites on the polymer are effective at 0.12 ionic strength, while at 0.02 ionic strength, $80 \%$ are effective ${ }^{26}$ (see original work for the specific calculation). The effects of $\mathrm{pH}$ and ionic strength on molecular shape have been reported. ${ }^{10,13,15,17,19,21,25,27-29}$ Generally, the coil expands at low ionic strength and high $\mathrm{pH}$ (larger radius of gyration) with a corresponding increase in the viscosity. The bouyant density of $\mathrm{HA}$ is reported to decrease with the addition of a counterion in the equilibrium density gradient centrifuge. ${ }^{19}$ Circular dichroism and optical rotatory dispersion studies on HA also suggest that conformational transitions may accompany changes in solution $\mathrm{pH}$ and ion concentration. ${ }^{30-37}$ Infrared dichroism studies ${ }^{38}$ indicate conformational alterations occur in $\mathrm{HA}$ with variation of $\mathrm{pH}$ and ionic strength. Solutions of sodium hyaluronate have been shown to act as mechanical transducers, transforming a displacement pressure in the presence of surface adhesion to an electrical potential; this suggests a mechanically induced entropy driven conformational change. ${ }^{39}$ In addition, the strained HA salt seems to adopt a less entropic configuration with a reversible loss of bound water. ${ }^{40}$

Solution NMR studies have been reported on sodium hyaluronate. ${ }^{41}$ The results have been interpreted in terms of a model of covalentlydefined stiff segments within the HA chains. These stiff segments comprise $55-70 \%$ of the chain and are at least 60 disaccharide units long. These stiff segments can be made mobile by exposure to hyaluronidase or alkali.

Both electron microscopy and X-ray diffraction have been used to study HA in the solid state. EM studies ${ }^{13,42,43}$ show long fibrillar structures. X-ray diffraction investigations indicate HA exhibits extensive polymorphism. The free acid (low $\mathrm{pH}$ ) form shows a two-fold structure with a rise per disaccharide on the helix axis of $9.8 \AA .^{44,45}$ The sodium, potassium, and calcium salts exist in a variety of helical conformations and packing arrangements. Several threefold structures are reported. $^{44-47}$ These generally have a rise per monomer of $9.5 \AA$. Two four-fold forms also 
Conformational Analysis of Glycosaminoglycans. III.

have been reported, one with a rise per disaccharide of $9.28 \AA$, and the second with a reduced rise of only $8.50 \AA \AA^{48-50}$ The somewhat collapsed fourfold form was originally believed to be a double helical structure. ${ }^{4,49}$ However, recent rigidbody least square refinement ${ }^{50}$ has shown this form to be probably a single stranded structure. A similar refinement on a three-fold sodium hyaluronate has been performed. ${ }^{47}$ These two refined structures will be discussed later in detail.

Theoretical structural studies on HA have been quite limited. Rees ${ }^{51}$ did a rough torsion angle scan to locate allowable conformations based only upon steric interactions. Backbone conformational analysis excluding solvation effects, counter-ion effects, and side-chain torsional rotations have been reported by Cleland. ${ }^{52}$

\section{METHODS}

Three physico-chemical states for HA have been considered in our analyses: (1) $\mathrm{HA}^{-}$, ionized hyaluronate without a counter-ion, (neutral $\mathrm{pH}$ and low ionic strength), (2) HAH, un-ionized and uncharged HA (the low pH form); and (3) $\mathrm{HA}^{-}$. $\mathrm{Na}^{+}$ionized hyaluronate with sodium ion present (neutral $\mathrm{pH}$ and high ionic strength). The complete conformational analysis of each of these three forms was carried out using the CAMSEQ Software System. ${ }^{53,54}$ Briefly, the total conformational energy is calculated by CAMSEQ using pairwise nonbonded potential energy functions (described at length in ref 55) plus a set of torsional energy functions. There are five terms in the expression for the conformational energy in CAMSEQ. (1) The steric energy is approximated through a pseudo-Lennard-Jones 6-12 potential. (2) A Coulomb law-type potential is used to estimate the electrostatic energy with and without a Debye--Hückel screening potential:

$$
E_{i j}=\frac{q_{i} q_{j}}{\varepsilon r_{i j}} \exp \left(-k r_{i j}\right)
$$

where $q_{i}$ and $q_{j}$ are partial atomic charges which are calculated using the $\mathrm{CNDO} / 2^{56}$ method. $\varepsilon$ is the molecular dielectric constant held fixed at $3.5, r_{i j}$ is the interatomic distance, and $k$ is equal to either 0 (for a simple coulombic function) or the reciprocal of the normal contact distance, $1 / r_{\mathrm{c}}$ (for a Debye-Hückel type screening potential).
Table I. Atomic charge for the repeat units of the three forms of $\mathrm{HA}$

\begin{tabular}{|c|c|c|c|}
\hline ATOM & $\mathrm{HA}^{-}$ & HAH & $\mathrm{HA}^{-} \cdot \mathrm{Na}^{+}$ \\
\hline \multicolumn{4}{|c|}{$\begin{array}{l}\text { Glucuronic acid } \\
\text { moiety }\end{array}$} \\
\hline $\mathrm{C}^{\prime}$ & 0.296 & 0.296 & 0.293 \\
\hline $\mathbf{H} 1^{\prime}$ & -0.057 & -0.037 & -0.050 \\
\hline $\mathrm{C} 2^{\prime}$ & 0.117 & 0.120 & 0.106 \\
\hline $\mathbf{H} 2^{\prime}$ & -0.016 & 0.009 & -0.011 \\
\hline $\mathrm{O} 2^{\prime}$ & -0.261 & -0.256 & -0.257 \\
\hline $\mathrm{H}\left(\mathrm{O} 2^{\prime}\right)$ & 0.110 & 0.141 & 0.131 \\
\hline $\mathrm{C}^{\prime}$ & 0.139 & 0.136 & 0.132 \\
\hline $\mathrm{H}^{\prime}{ }^{\prime}$ & -0.033 & 0.001 & -0.007 \\
\hline O3' & -0.267 & -0.259 & -0.267 \\
\hline $\mathrm{H}\left(\mathrm{O}^{\prime}\right)$ & 0.098 & 0.129 & 0.124 \\
\hline $\mathrm{C} 4^{\prime}$ & 0.152 & 0.139 & 0.144 \\
\hline $\mathrm{H} 4^{\prime}$ & -0.018 & -0.010 & -0.018 \\
\hline $\mathrm{C} 5^{\prime}$ & 0.081 & 0.108 & 0.087 \\
\hline $\mathrm{H} 5^{\prime}$ & -0.048 & -0.007 & -0.021 \\
\hline $\mathrm{O}^{\prime}$ & -0.248 & -0.235 & -0.241 \\
\hline $\mathrm{C} 6^{\prime}$ & 0.367 & 0.418 & 0.425 \\
\hline O6' & -0.559 & -0.353 & -0.470 \\
\hline $\mathrm{O}^{\prime}$ & -0.554 & -0.250 & -0.470 \\
\hline $\mathrm{H}^{\prime}\left(\mathrm{O}^{\prime}\right)$ & & 0.157 & \\
\hline $\mathrm{Na}$ & & & 0.639 \\
\hline \multicolumn{4}{|c|}{ Linkage oxygens } \\
\hline $04^{\prime} ; \beta-\mathrm{D}-(1 \rightarrow 4)$ & -0.231 & -0.214 & -0.211 \\
\hline $03 ; \beta-\mathrm{D}-(1 \rightarrow 3)$ & -0.249 & -0.208 & -0.239 \\
\hline $\begin{array}{l}\text { Glucosamine } \\
\text { moiety }\end{array}$ & & & \\
\hline
\end{tabular}


The technique for calculating atomic charges using $\mathrm{CNDO} / 2$ for the relatively large di- and trisaccharide units is discussed elsewhere ${ }^{57}$ with the results for $\mathrm{HA}^{-}$presented. Deviations from those results for $\mathrm{HAH}$ and $\mathrm{HA}^{-} \cdot \mathrm{NA}^{+}$are reported in Table I. (3) The hydrogen bond energy is computed via a "corrected sum" hydrogen bond potential function:

$$
E_{\mathrm{hb}}=\frac{-A}{r^{6}}+\frac{B}{r^{12}}+\frac{q_{\mathrm{h}} q_{\mathrm{a}}}{\varepsilon r}-\left[\frac{-A_{0}}{r^{6}}+\frac{B_{0}}{r^{12}}\right] f\left(\phi_{1}, \phi_{2}\right)
$$

where $r$ is the distance between the hydrogen and the "acceptor" atom, $A$ and $B$ are the appropriate Lennard-Jones parameters, $q_{\mathrm{h}}$ and $q_{\mathrm{a}}$ are the hydrogen and acceptor atom electronic charges, $\varepsilon$ is the molecular dielectric constant and $A_{0}$ and $B_{0}$ are constants which need to be evaluated. The function $f\left(\phi_{1}, \phi_{2}\right)$ is selected to be totally separable.

$$
f\left(\phi_{1}, \phi_{2}\right)=f\left(\phi_{1}\right) \cdot f\left(\phi_{2}\right)
$$

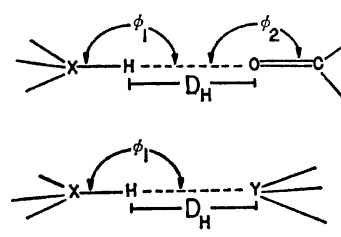

Figure 2. Description of hydrogen bonding geometry. Two possible hydrogen bonds are considered. See text for a discussion.

Two cases exist for the definition of $\phi_{1}$ and $\phi_{2}$. Figure 2a shows a $\mathrm{X}-\mathrm{H} \cdots \mathrm{O}=\mathrm{Y}$ type hydrogen bond, where $\phi_{1}$ is the angle between $\mathrm{X}-\mathrm{H} \cdots \mathrm{O}$ and $\phi_{2}$ is defined as the $\mathrm{H}-\mathrm{O}-\mathrm{Y}$ angle. A linear hydrogen bond is defined as optimal. When the acceptor atom is divalent (or higher) $\phi_{2}$ is no longer uniquely defined. We thus set $f\left(\phi_{2}\right)=1$ for this case. See Figure 2b. Only $A_{0}$ and $B_{0}$ need to be defined. These are calculated by first defining an optimum hydrogen-acceptor distance $D_{\mathrm{H}}$ and an optimum energy $E_{0}$; then

$$
E \equiv E_{0} \text { at } D_{\mathrm{H}}
$$

and

$$
\partial E / \partial r \equiv 0 \text { at } D_{\text {H }}
$$

and $A_{0}$ and $B_{0}$ can be defined. We have used $E_{0}=-3.5 \mathrm{kcal} / \mathrm{mol}$ and $D_{\mathrm{H}}=1.75 \AA$ (see ref 55 ). (4). Torsional energy contributions for rotations about the glycosidic linkage bonds were calculated previously for the $\beta-\mathrm{D}(1 \rightarrow 4)$ linkage $^{57}$ and for the $\beta-D(1 \rightarrow 3)$ linkage. ${ }^{58}$ (4). Solvation energetics were estimated using the hydration shell model. $^{55}$ In this model, the solvation energy is defined as the sum over the entire solute molecule of the energies contributed by the exclusion of solvent molecules from the hydration shell about each composite solute group.

The inclusion of a sodium ion in the vicinity of the carboxyl group of HA presented a difficult problem. Potential energy functions involving ions are not very well defined at present. We decided on a very simplistic approach. The sodium ion was introduced into the calculations as an additional solute atom. $\mathrm{CNDO} / 2$ calculations indicate $\mathrm{Na}^{+}$counter-ions energetically prefer complexing coplanar to the carboxyl groups $3.1 \AA$ from the carbon, along the $\mathrm{C}_{5}-\mathrm{C}_{6}$ bond vector to the glucuronic acid moiety. ${ }^{59}$ The nonbonded interaction parameters for $\mathrm{Na}^{+}$-participating pairs have been calculated ${ }^{60,61}$ and are reported in Table II. Table I contains the atomic charge

Table II. Lennard-Jones steric potential energy function $^{2}$

(tFor the sodium ion (derived from) references 60 and 61)

\begin{tabular}{lrrr}
\hline & $A_{i j}$ & \multicolumn{1}{c}{$B_{i j}$} & $\mathbf{R}_{0}$ \\
\hline $\mathrm{Na}-\mathrm{H}$ & 32.0 & 1259.0 & 2.07 \\
$\mathrm{Na}-\mathrm{C}$ (SP3) & 115.0 & 19028.0 & 2.63 \\
$\mathrm{Na}-\mathrm{C}$ (SP2) & 107.0 & 12447.0 & 2.48 \\
$\mathrm{Na}-\mathrm{N}$ & 110.0 & 10766.0 & 2.41 \\
$\mathrm{Na}-\mathrm{O}(\mathrm{SP})$ & 90.0 & 7200.0 & 2.33 \\
$\mathrm{Na}-\mathrm{O}(\mathrm{SP} 2)$ & 90.0 & 7200.0 & 2.33 \\
$\mathrm{Na}-\mathrm{S}$ & 1300.0 & 269085.0 & 2.73 \\
\hline
\end{tabular}

${ }^{\mathrm{a}}$ The Lennard-Jones function is $E_{i j}=B_{i j} / r_{i j}^{12}-A_{i j} / r_{i j}^{6}$. $R_{0}$ is the distance, $r_{i j}$, for which the energy is a minimum.

Table III. Parameters for the sodium ion for the hydration shell model solvation energy function (derived from ref 59)

\begin{tabular}{ll}
\hline Radius of $\mathrm{Na}^{+}$ & $r=0.98 \AA$ \\
Energy for removal of each water & $\Delta f=32.98 \mathrm{kcal} / \mathrm{mol}$ \\
Number of water molecules & $n=4$ \\
Hydration shell radius & $R_{\mathrm{v}}=4.46 \AA$ \\
$\begin{array}{l}\text { Excluded volume about } \mathrm{Na}^{+} \text {per } \\
\quad \text { water molecule }\end{array}$ & $V_{\text {exc }}=69.93 \AA$ \\
\hline
\end{tabular}


distribution differences for $\mathrm{HA}^{-} \cdot \mathrm{Na}^{+}$from $\mathrm{HA}^{-}$. Solvation parameters for $\mathrm{Na}^{+}$were derived from experimental data ${ }^{62}$ and are listed in Table III.

The electrostatic potential function used to describe ion-involved interactions is of prime concern. The Debye-Hückel screening potential (i.e., $k=r_{c}{ }^{-1}$ ) was used in the calculations in order to examine the influence of the charge potential upon the structural stability of the macroionsolvent complex. Hesselink, et al., ${ }^{63}$ and Rao and Miller $^{67}$ each empolyed a Debye-Hückel screening potential to describe the electrostatic interactions involving charged groups in their respective conformational analyses of charged poly(L-lysine) and charged poly(L-glutamic acid). Our concern was that the long range strength of interactions involving the sodium ions might be overemphasized by the usual coulombic function $(k=0)$. We tried both $K=0$ and $k=r_{c}{ }^{-1}$, the atomic contact distance. The results for $k=r_{c}{ }^{-1}$ suggested we had an almost totally collapsed structure, with large, oligomeric ring complexes predicted. This indicated we were probably overcompensating for ion-charge smearing. In fact, at distances over $4 \AA$, the value of the electrostatic energy was negligible, excluding possible nearest neighbor charge repulsions. Since CNDO/2 had been used to calculated a $\mathrm{Na}^{+}$residual charge of +.639 (instead of +1.0 for an uncomplexed ion which is more relevant to the Debye-Hückel theory) we felt that we had probably introduced an effective smearing of the ion's charge field in the charge calculation. Thus, we abandoned the Debye-Hückel screening potential, and used $k=0$ in all subsequent calculations. It should be emphasized that the calculated magnitude of the electrostatic energy in both the $\mathrm{HA}^{-} \cdot \mathrm{Na}^{+}$forms and the corresponding preferential conformational state, is very sensitive to the degree of shielding/ charge smearing employed in the empirical electrostatic energy function.

The valence geometry of the saccharides was fixed in the $\mathrm{Cl}$ chain conformation. Bond angles for the glycosidic linkages were set according to the values calculated previously. ${ }^{58}$ All rotations are reported as clockwise. The reference state is that for which the glycosidic linkage bond rotations are zero when $\mathrm{H}-\mathrm{C}-\mathrm{O}-\mathrm{C}$ bonds are cis. All side group bond rotations are defined as zero for the trans conformer. Initial studies were performed on the disaccharide shown in Figure 1. This gave some indication of the conformational behavior of the $\beta$-D $(1 \rightarrow 4)$ linkage $\left(\theta_{1}, \theta_{2}\right)$ with respect to the carboxyl $\left(\tau_{1}\right)$ and $N$-acetyl $\left(\tau_{2}\right)$ pendent groups which are in close proximity across this linkage. Generally, conformational preferences for this linkage were available from previous work. ${ }^{57}$ The $\beta$-D $(1 \rightarrow 3)$ linkage was similarly studied, using a disaccharide model. ${ }^{58}$ The disaccharide studies aided in reducing the volume of conformational hyperspace required for the complete conformational analysis. These rough scans reduced $\theta_{1}$-space to the range $-30^{\circ}$ to $120^{\circ}, \theta_{2}$-space to $-240^{\circ}$ to $80^{\circ}, \theta_{3}$-space to $-30^{\circ}$ to $180^{\circ}$, and $\theta_{4}$-space to $-70^{\circ}$ to 200 . This reduces the volume of the hyperspace of over $1.6 \times 10^{10}$ degrees ${ }^{4}$ by $83.8 \%$.

The trisaccharide unit shown in Figure 3 was used to approximate the conformational behavior of the polymer. It contains all nearest neighbor interactions present in the polymer. While a disaccharide ( $\mathrm{AB}$ or $\mathrm{BA}$ ) would neglect certain interactions, a tetramer, e.g., (ABAB) would overestimate certain of the interactions (BA occurs

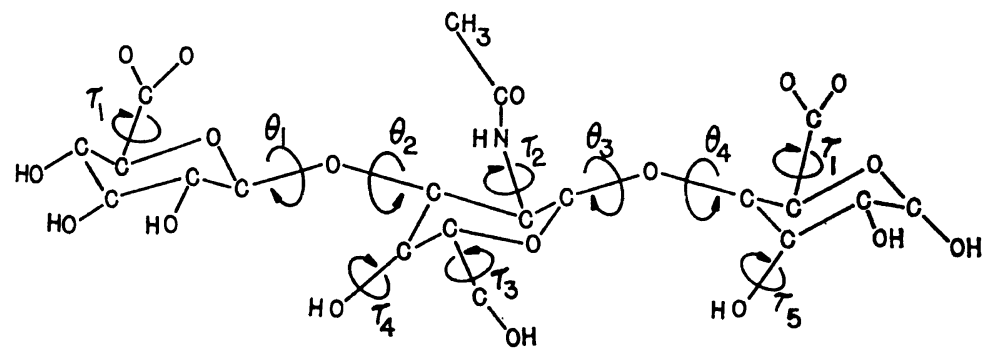

Figure 3. The trisaccharide model used to approximate the hyaluronic acid polymer in our calculations. The rotatable bonds in the polymer backbone are $\theta_{1}$ and $\theta_{2}$ for the $\beta-\mathrm{D}-(1 \rightarrow 4)$ linkage and $\theta_{3}$ and $\theta_{4}$ for the $\beta$-D- $(1 \rightarrow 3)$ linkage. The allowed side-chain rotations are indicated by $\tau$. 
once in the middle, $\mathrm{AB}$ occurs on each end). But the trisaccharide eliminates the further next-tonearest neighbor interaction. ABA contains no B-B interaction, while including $\mathbf{A}-\mathbf{A}$. But both $\mathrm{AB}$ and $\mathrm{BA}$ are present once. Now consider that $A$ is charged (the glucuronic acid unit) and $B$ is not (the $N$-acetyl glucosamine). The $\mathrm{A}-\mathrm{A}$ or B-B distance is $6-10 \AA$. A-A contains strong electrostatic terms which are not negligible at these distances. But B-B has only short range steric and electrostatic interactions which approach zero. Thus a trisaccharide ABA will be a reasonable nearest-neighbor model for HA while allowing a considerably easier calculation. The trisaccharide model of HA was thus chosen. Those bond rotations considered in our studies are indicated in Figure 3. Four of the rotations are backbone rotations $(\theta)$ and five are pendent group rotations $(\tau) . \quad \tau_{1}$ and $\tau_{2}$ are the most significant side chain rotations. $\tau_{4}$ and $\tau_{5}$ rotations will produce intramolecular hydrogen bonds to the ring oxygen of the adjacent saccharide.

The scheme of collection and subsequent use of conformational energy data for a structure of the complexity of HA is by no means trivial. The conformational sampling techniques can have profound influence on the results. Our main goal was to estimate the partition function of each physico-chemical form of HA which, for a fixed valence geometry, is formally defined as

$$
Z \equiv \frac{1}{V} \int \ddot{V}_{V} \int \exp \left(-\beta E\left(\theta_{1} \cdots \theta_{n}\right)\right) \mathrm{d} \theta_{1} \cdots \mathrm{d} \theta_{n}
$$

where $(\theta)$ are the torsional rotation angles, $V$ is the associated volume of conformational space, $E\left(\theta_{1} \cdots \theta_{n}\right)$ the conformational energy, and $\beta=1 / R T$. In this work $Z$ was approximated as

$$
Z \cong \sum_{i=1}^{S} \frac{m_{i} \exp \left(-\beta E_{i}\right)}{N}
$$

where

$$
N=\sum_{i=1}^{S} m_{i}
$$

$S$ is the number of energy partitions of size $\Delta E$ considered, and $m_{i}$ the number of conformations possessing an energy between $\left(E_{i}-1 / 2 \Delta E\right)$ and $\left(E_{i}\right.$ $+1 / 2 \Delta E$ ). Correspondingly, the probability of observing any conformation possessing an energy in the $i$ th interval is

$$
P_{i}=\frac{\exp \left(-\beta E_{i}\right)}{Z}
$$

To evaluate a value for $Z$ using eq 4 requires knowledge of the absolute minimum energy conformation and the size of the conformational sample. We have attempted to determine this requisite information using two sampling procedures: First, we performed an initial nonrandom conformational search in an attempt to identify the various local energy minima. A three-step procedure derived for simpler molecules in our laboratory was used. ${ }^{53}$ It is a combination of sequential scans and pseudo-random minimizations coupled with a gradient-search minimization ${ }^{65}$ of the conformational energy. This was done for each of the three physicochemical forms of HA, giving 2000-3000 conformations. These were very rich in local minima like some nonhomopolypeptides. ${ }^{66}$ Secondly, sets of 10,000 random conformations were collected for each of the three forms of HA. When the findings from these two independent sampling procedures were compared, only very minor differences were found with respect to the types of conformations that were of corresponding lowest energy in each sample set. However, the 10,000 conformation sets are statistically more reliable and directly comparable to one another. They were used to estimate $Z$. The initial data sets, employing nonrandom sampling of the conformational hyperspace, could not be used to evaluate $Z$, but did provide an independent means of checking our purely random sampling procedure.

In the presentation of the results of the random data sets we include the backbone torsion angles and the two major side chain angles $\left(\tau_{1}, \tau_{2}\right)$. We also list the energy difference from the minimum as well as the state-probabilities. Free space (in vacuo) results are not always the same as the aqueous solution ordering, so both are reported. Conformations are ranked from most probable to least probable (to $0.2 \%$ probability). In addition, as a means of comparison, we include the helical parameter for each conformation (calculated according to the method of ref 67). That is, we assume the conformation in question persists for the entire length of the chain and calculate the corresponding number of monomers (disaccharides) per turn of the helix $(r)$, the rise per 
monomer in $\AA(d)$, the radius of the helix (distance from the $\beta(1 \rightarrow 4)$ glycosidic oxygen to the helix axis) in $\AA(\rho)$, and the chirality (right or left handed) (C). Also presented is $l_{0}$, the length of the monomer (from $\beta(1 \rightarrow 4)$ glycosidic oxygen to the adjacent $\beta(1 \rightarrow 4)$ glycosidic oxygen). Using these parameters the ORTEP Fortran package ${ }^{68}$ was used to generate spatial models of these conformations. The helix axis was also drawn to provide a three dimensional perspective. Figure 4 contains an ORTEP drawing of a monomer with the atoms labeled for reference.

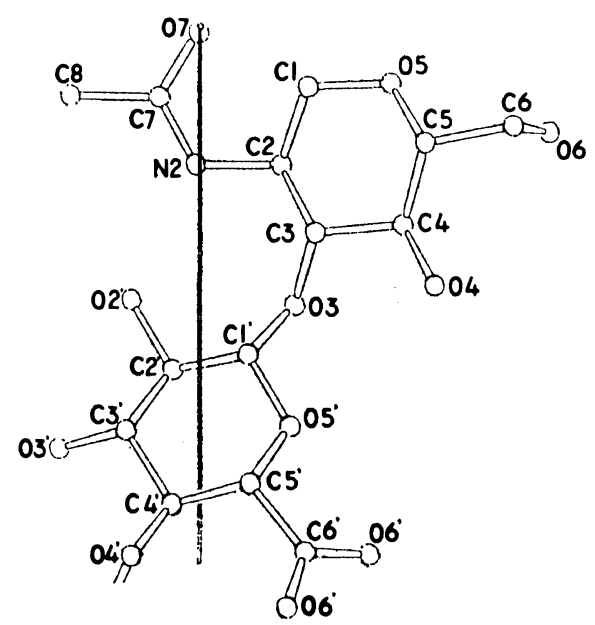

Figure 4. ORTEP drawing of the basic monomer of HA with atoms labeled for reference for Figures 5-7 and 10.

The chain statistical properties of the forms of HA have been calculated for comparison with experimental hydrodynamic data. This is accomplished from the probability data by assuming that for an $n$-mer of $\mathrm{HA}$, conformation $i$, which has a probability $\boldsymbol{P}_{i}$, will occur $n \boldsymbol{P}_{i}$ times in the polymer. However, the location of $i$ in the chain is purely random.

Chains possessing the predicted frequencies of occurence of each monomer conformation were randomly generated for each polymer. Calculations for the 50-mer, $100,200,300,500,750,1000$, 1500 , and 2000-mer were performed. The end-toend distance was calculated and saved for each chain. Four hundred model chains were generated for each molecular weight and the average length and standard deviation were calculated. The average length of the monomer, $\left\langle l_{0}\right\rangle$, was also determined, so that the characteristic ratio could be estimated from

$$
C_{n}=\frac{\left\langle R_{0}{ }^{2}\right\rangle}{n\left\langle l_{0}\right\rangle^{2}}
$$

\section{RESULTS}

HA was found to be a very rigid molecule in regard to the limited range of sterically allowed $\theta$ values. This is consistent with the findings of Rees, ${ }^{51}$ who has suggested that over $90 \%$ of conformational hyperspace is inaccessible to polysaccharides due to steric hinderance. HA, in all three forms, appears to be restricted to relatively small volumes of four dimensional, backbone conformational hyperspace (four backbone rotations, plus two major side group rotations, $\tau_{1}$, and $\tau_{2}$, plus three minor rotations, $\left(\tau_{3}-\tau_{5}\right)$. In the limited volume of torsional hyperspace which yields low energy conformations for the HA, large variations in helical structure occur. Thus, the local energy minima close to one another in $\theta$-space can be geometrically quite diverse.

The results of the conformational analyses of the three forms of HA are summarized in Tables IV through VI. These results are taken from the second, randomly generated, data set. However, we reiterate that the corresponding types of conformations are virtually identical for the two data sets. These qualitative observations for each form of HA can be summarized: $\mathrm{HA}^{-}$: We began with the investigation of the ionized form of $\mathrm{HA}$ in which the counter-ion was absent. This form occurs at neutral $\mathrm{pH}$ and low ionic strength, as suggested by the electrophoresis data discussed earlier. ${ }^{26}$ Solution studies on the neutral $\mathrm{pH}$, low ionic strength HA samples discussed earlier show HA to be a fairly rigid rod. Our results are listed in Table IV(A-B). The conformations allowable for this form of HA are generally quite extended. A wide variety of conformations do exist. The effect of our solvation energy term appears small, with only a few conformations varying. Howeyer, solvation induces a more rigid distribution of conformers. Several of these conformations are shown in Figure 5.

HAH: The second chemical form studied is the uncharged low $\mathrm{pH}$ form. This form is found 


\section{R. Potenzone, Jr. and A. J. Hopfinger}

Table IV (A). Conformations of highest statistical weights for $\mathrm{HA}^{-}$ (in solution). See text for a discussion

\begin{tabular}{|c|c|c|c|c|c|c|c|c|c|c|c|c|c|c|c|}
\hline \multirow{2}{*}{$\begin{array}{c}\text { Confor- } \\
\text { mation } \\
\text { No. }\end{array}$} & \multicolumn{2}{|c|}{$\beta(1 \rightarrow 4)$} & \multicolumn{2}{|c|}{$\beta(1 \rightarrow 3)$} & \multirow{2}{*}{$\tau_{1}$} & \multirow{2}{*}{$\tau_{2}$} & \multicolumn{2}{|c|}{ Solution } & \multicolumn{2}{|c|}{ Free space } & \multicolumn{5}{|c|}{ Helical parameters } \\
\hline & $\theta_{1}$ & $\theta_{2}$ & $\theta_{3}$ & $\theta_{4}$ & & & En & $\operatorname{Prc}$ & Energy & y $P$ & $r$ & $d$ & $\rho$ & $C$ & $l_{0}$ \\
\hline 1 & 21 & 297 & 74 & 26 & 41 & 201 & 0 & 83.7 & 0 & 58.3 & 2.5 & 8.8 & 1.2 & $\mathrm{~L}$ & 9.1 \\
\hline 2 & 40 & 345 & 18 & 314 & 141 & 188 & 1.92 & 3.7 & 1.19 & 8.4 & 2.0 & 10.0 & 0.71 & $\mathbf{R}$ & 10.1 \\
\hline 3 & 29 & 323 & 67 & 354 & 148 & 210 & 2.05 & 3.0 & 1.28 & 7.3 & 2.4 & 9.45 & 1.13 & L & 9.7 \\
\hline 4 & 54 & 1 & 331 & 338 & 103 & 179 & 2.16 & 2.5 & 1.84 & 2.9 & 2.1 & 9.7 & 0.63 & $\mathbf{R}$ & 9.8 \\
\hline 5 & 45 & 321 & 26 & 8 & 136 & 189 & 2.29 & 2.0 & 1.51 & 5.0 & 2.3 & 9.6 & 0.43 & $\mathrm{~L}$ & 9.6 \\
\hline 6 & 40 & 326 & 28 & 312 & 115 & 171 & 2.54 & 1.4 & 1.55 & 4.7 & 2.3 & 10.0 & 0.67 & $\mathbf{R}$ & 10.1 \\
\hline 7 & 56 & 335 & 12 & 312 & 78 & 160 & 2.71 & 1.0 & 1.51 & 5.1 & 2.2 & 10.02 & 0.64 & $\mathbf{R}$ & 10.1 \\
\hline 8 & 49 & 345 & 73 & 42 & 130 & 177 & 3.09 & 0.6 & 3.30 & 0.3 & 4.1 & 6.9 & 3.81 & L & 8.7 \\
\hline 9 & 29 & 320 & 64 & 14 & 34 & 181 & 3.23 & 0.4 & 2.42 & 1.1 & 2.6 & 9.1 & 1.2 & $\mathrm{~L}$ & 9.4 \\
\hline 10 & 93 & 340 & 59 & 7 & 40 & 195 & 3.47 & 0.3 & 1.9 & 2.7 & 4.7 & 9.5 & 0.8 & L & 9.5 \\
\hline 11 & 33 & 330 & 61 & 357 & 46 & 194 & 3.59 & 0.2 & 2.04 & 2.1 & 2.5 & 9.5 & 1.1 & $\mathrm{~L}$ & 9.7 \\
\hline 12 & 67 & 24 & 346 & 321 & 148 & 177 & 3.85 & 0.2 & 3.99 & 0.1 & 2.3 & 10.0 & 0. & L & 10.0 \\
\hline 13 & 64 & 16 & 16 & 313 & 11 & 175 & 3.65 & 0.2 & 2.92 & 0.5 & 2.4 & 10.0 & 0.7 & L & 10.1 \\
\hline 14 & 37 & 23 & 28 & 303 & 173 & 178 & 3.84 & 0.2 & 3.00 & 0.4 & 2.2 & 9.8 & 1.2 & $\mathrm{~L}$ & 10.1 \\
\hline
\end{tabular}

Table IV (B). Conformations of highest statistical weights for $\mathrm{HA}^{-}$ (in free space). See text for a discussion

\begin{tabular}{|c|c|c|c|c|c|c|c|c|c|c|c|c|c|c|c|}
\hline \multirow{2}{*}{$\begin{array}{c}\text { Confor- } \\
\text { mation } \\
\text { No. }\end{array}$} & \multicolumn{2}{|c|}{$\beta(1 \rightarrow 4)$} & \multicolumn{2}{|c|}{$\beta(1 \rightarrow 3)$} & \multirow{2}{*}{$\tau_{1}$} & \multirow{2}{*}{$\tau_{2}$} & \multicolumn{2}{|c|}{ Solution } & \multicolumn{2}{|c|}{ Free space } & \multicolumn{5}{|c|}{ Helical parameters } \\
\hline & $\theta_{1}$ & $\theta_{2}$ & $\theta_{3}$ & $\theta_{4}$ & & & Energy & Prol & Energy & Prob. & $r$ & $d$ & $\rho$ & $C$ & $l_{0}$ \\
\hline 1 & 21 & 297 & 74 & 26 & 41 & 201 & 0.0 & 83.7 & 0.0 & 58.3 & 2.5 & 8.3 & 1.2 & L & 9.1 \\
\hline 2 & 40 & 354 & 18 & 314 & 141 & 188 & 1.92 & 3.7 & 1.19 & 8.4 & 2.0 & 10.0 & 0.7 & $\mathbf{R}$ & 10.1 \\
\hline 3 & 29 & 323 & 67 & 354 & 148 & 210 & 2.05 & 3.0 & 1.28 & 7.3 & 2.4 & 9.5 & 1.1 & L & 9.7 \\
\hline 4 & 56 & 335 & 12 & 312 & 78 & 160 & 2.71 & 1.0 & 1.51 & 5.1 & 2.2 & 10.0 & 0.6 & $\mathbf{R}$ & 10.1 \\
\hline 5 & 45 & 321 & 26 & 8 & 136 & 189 & 2.29 & 2.0 & 1.51 & 5.0 & 2.3 & 9.6 & 0.4 & $\mathrm{~L}$ & 9.6 \\
\hline 6 & 40 & 326 & 28 & 312 & 115 & 171 & 2.54 & 1.4 & 1.55 & 4.7 & 2.3 & 10.0 & 0.7 & $\mathbf{R}$ & 10.1 \\
\hline 7 & 54 & 1 & 331 & 338 & 107 & 192 & 2.16 & 2.51 & 1.84 & 2.9 & 2.1 & 9.7 & 0.6 & $\mathbf{R}$ & 9.8 \\
\hline 8 & 93 & 340 & 59 & 7 & 40 & 195 & 3.47 & 0.3 & 1.9 & 2.7 & 4.7 & 9.5 & 0.8 & $\mathrm{~L}$ & 9.5 \\
\hline 9 & 33 & 330 & 61 & 357 & 46 & 194 & 3.59 & 0.2 & 2.04 & 2.1 & 2.5 & 9.5 & 1.1 & L & 9.7 \\
\hline 10 & 29 & 320 & 64 & 14 & 34 & 181 & 3.23 & 0.4 & 2.42 & 1.1 & 2.6 & 9.1 & 1.2 & L & 9.4 \\
\hline 11 & 64 & 16 & 16 & 313 & 11 & 175 & 3.65 & 0.2 & 2.92 & 0.5 & 2.4 & 10.0 & 0.7 & $\mathrm{~L}$ & 10.0 \\
\hline 12 & 89 & 355 & 20 & 338 & 91 & 149 & 4.34 & 0.1 & 2.96 & 0.5 & 2.9 & 9.9 & 0.7 & $\mathbf{L}$ & 10.0 \\
\hline 13 & 37 & 23 & 28 & 303 & 173 & 178 & 3.84 & 0.2 & 3.0 & 0.4 & 2.2 & 9.8 & 1.2 & $\mathbf{L}$ & 10.1 \\
\hline 14 & 49 & 345 & 73 & 42 & 130 & 177 & 3.09 & 0.6 & 3.3 & 0.3 & 4.1 & 6.9 & 3.8 & $\mathbf{L}$ & 8.7 \\
\hline 15 & 24 & 317 & 55 & 5 & 14 & 176 & 5.26 & 0 & 3.55 & 0.2 & 2.3 & 9.4 & 1.1 & $\mathbf{L}$ & 9.6 \\
\hline 16 & 23 & 337 & 43 & 20 & 122 & 198 & 5.0 & 0 & 3.6 & 0.2 & 2.5 & 9.0 & 1.4 & $\mathbf{L}$ & 9.4 \\
\hline
\end{tabular}

to crystallize as an extended two-fold structure. Solution studies suggest a less rigid, more random coil structure than $\mathrm{HA}^{-}$. In fact, the results in Table V(A-B) suggest that HAH is locally less rigid than $\mathrm{HA}^{-}$. There are several energetically closely spaced, yet structurally diverse helical states available to the biopolymer. Figure 6 illustrates some of these structures. These helices are less extended along the chain axis than those of $\mathrm{HA}^{-}$. Aqueous interactions appear to have an appreciable effect on the structure. There is considerably less conformational flexibility in solution.

$\mathrm{HA}^{-} \cdot \mathrm{Na}^{+}$: The sodium salt of $\mathrm{HA}$ was the last form studied. It corresponds to neutral $\mathrm{pH}$ and moderate to high ionic strength. This 

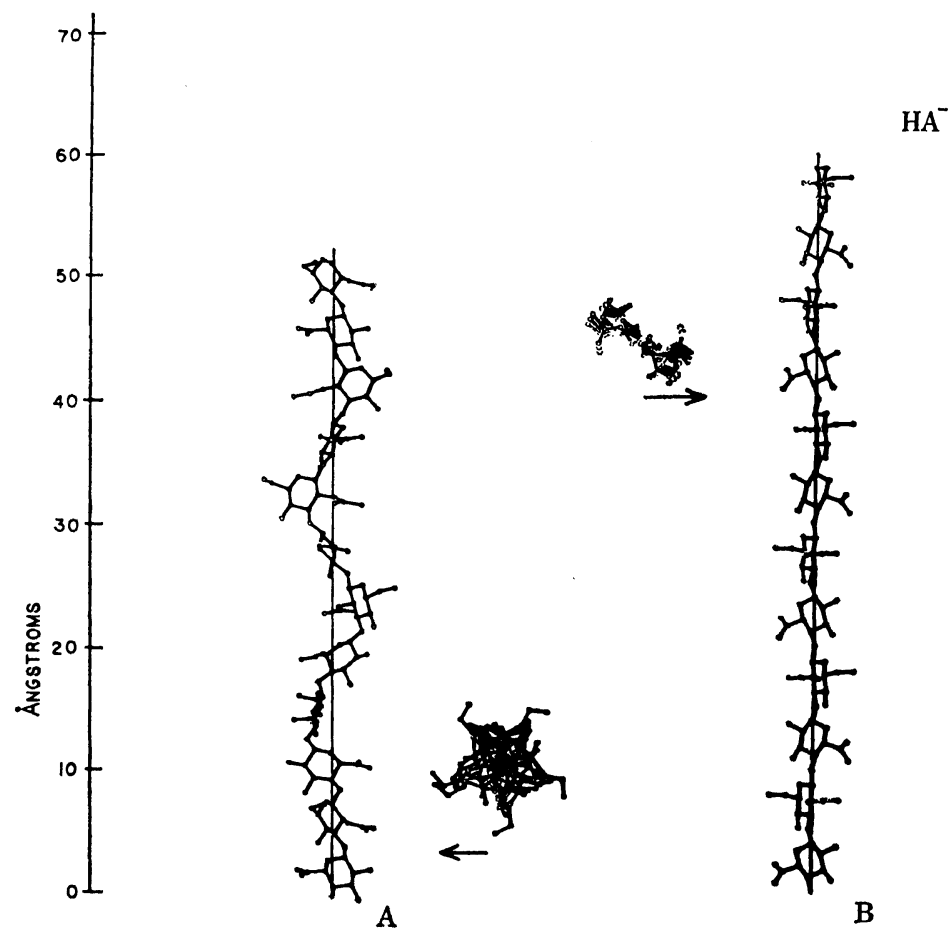

Figure 5. ORTEP drawings of two projections of the two most probable conformations for the $\mathrm{HA}^{-}$model. (a) corresponds to conformation No. 1 and (b) corresponds to conformation No. 2 in Tables IV(A) and IV(B). The scale in Ångstroms is shown.

chemical form is nearest to the physiological occurrence of the biopolymer. Solution studies suggest a more random coil-type structure than the other forms. X-ray diffraction studies indicate a few varied, but still fairly extended structures. Our calculations suggest this form to be more flexible in adopting different conformations than both HAH and $\mathrm{HA}^{-}$. Solvent dependent calculations show higher probabilities for the minimum. A totally different set of conformations are predicted in free space. These results are shown in Figure 7 and in Tables VI(A) and (B). In solution the most probable conformation calculated (Figure 7a) is a $13_{2}$ left-handed helix with a short axial rise per dissacharide, $5.0 \AA$. This conformer has an $89.1 \%$ thermodynamic probability. The sodium ion and carboxyl group are on the interior of the helix, as are the $\mathrm{N}$-acetyl units. However, the $\mathrm{N}$-acetyl points away from the carboxyl so as not to impinge on the hydration shell of the sodium ion. In the free-space model where hydration is not considered, the $N$-acetyl group moves close to the carboxyl group, thus reducing the electrostatic energy term. The helix expands and the sodium complex moves to the exterior of the helix.

We next calculated the chain statistics. The results are listed in Table VII. The characteristic ratios are plotted for $\mathrm{HA}^{-}$in Figure 8a and for $\mathrm{HA}^{-} \cdot \mathrm{Na}^{+}$in Figure 9. Figures $8 \mathrm{~b}$ and $\mathrm{c}$ show how $C_{500}$ is affected as more chains are generated. $C_{n}$ plots of $\mathrm{HA}^{-}$and $\mathrm{HA}^{-} \cdot \mathrm{Na}^{+}$possess similar shapes to curves predicted for many other polymers. ${ }^{69} \mathrm{HAH}$, however, as can be seen in Table VII, yields a constant value of $C_{n}$ over the entire range of $n$ sampled. Further, the $C_{n}$ of the solvent dependent calculation yields a value of 0.3 , a range where highly structured, compact globular proteins occur. The predicted structure is considerably more compact than a random coil model. This unusual prediction can be understood by examining the most probable conformation for $\mathrm{HAH}$, which is a "circular" molecule six disaccharide units 


\section{R. Potenzone, Jr. and A. J. Hopfinger}

Table V (A). Conformations of highest statistical weights for HAH

(in solution). See text for a discussion

\begin{tabular}{|c|c|c|c|c|c|c|c|c|c|c|c|c|c|c|c|}
\hline \multirow{2}{*}{$\begin{array}{c}\text { Confor- } \\
\text { mation } \\
\text { No. }\end{array}$} & \multicolumn{2}{|c|}{$\beta(1 \rightarrow 4)$} & \multicolumn{2}{|c|}{$\beta(1 \rightarrow 3)$} & \multirow{2}{*}{$\tau_{1}$} & \multirow{2}{*}{$\tau_{2}$} & \multicolumn{2}{|c|}{ Solution } & \multicolumn{2}{|c|}{ Free space } & \multicolumn{5}{|c|}{ Helical parameters } \\
\hline & $\theta_{1}$ & $\theta_{2}$ & $\theta_{3}$ & $\theta_{4}$ & & & Energy & Prob. & Energy & Prob. & $r$ & $d$ & $\rho$ & $C$ & $l_{0}$ \\
\hline 1 & 78 & 28 & 86 & 40 & 158 & 163 & 0 & 75.9 & 0 & 41.6 & 6.0 & 0.66 & 8.6 & $\mathbf{R}$ & 8.6 \\
\hline 2 & 74 & 7 & 84 & 28 & 131 & 189 & 0.92 & 17.0 & 0.53 & 17.5 & 6.4 & 4.8 & 7.9 & $\mathrm{~L}$ & 8.9 \\
\hline 3 & 53 & 21 & 59 & 24 & 43 & 160 & 2.22 & 2.1 & 1.03 & 7.9 & 4.5 & 6.8 & 4.8 & $\mathbf{L}$ & 9.2 \\
\hline 4 & 50 & 6 & 80 & 48 & 175 & 159 & 2.52 & 1.3 & 1.9 & 9.6 & 4.5 & 3.9 & 5.8 & L & 8.4 \\
\hline 5 & 72 & 349 & 87 & 39 & 174 & 190 & 2.72 & 0.9 & 2.30 & 1.0 & 5.9 & 5.3 & 6.7 & L & 8.6 \\
\hline 6 & 49 & 337 & 76 & 37 & 120 & 192 & 2.96 & 0.6 & 1.63 & 2.9 & 3.7 & 7.5 & 3.1 & L & 8.8 \\
\hline 7 & 53 & 343 & 54 & 35 & 104 & 164 & 3.12 & 0.5 & 1.56 & 3.3 & 3.7 & 8.3 & 2.3 & $\mathrm{~L}$ & 9.0 \\
\hline 8 & 79 & 359 & 81 & 41 & 38 & 172 & 3.26 & 0.4 & 2.89 & 0.4 & 6.6 & 4.1 & 8.3 & $\mathbf{L}$ & 8.6 \\
\hline 9 & 59 & 354 & 81 & 28 & 140 & 145 & 3.44 & 0.3 & 1.8 & 2.2 & 4.8 & 6.8 & 4.7 & L & 8.9 \\
\hline 10 & 68 & 60 & 83 & 29 & 177 & 160 & 3.56 & 0.2 & 2.64 & 0.6 & 4.9 & 2.0 & 7.3 & $\mathbf{R}$ & 8.9 \\
\hline 11 & 57 & 8 & 359 & 314 & 40 & 150 & 3.83 & 0.2 & 1.47 & 3.8 & 2.1 & 10.0 & 0.6 & L & 10.1 \\
\hline
\end{tabular}

Table V (B). Conformations of highest statistical weights for $\mathrm{HAH}$

(in free space). See text for a discussion

\begin{tabular}{|c|c|c|c|c|c|c|c|c|c|c|c|c|c|c|c|}
\hline \multirow{2}{*}{$\begin{array}{c}\text { Confor- } \\
\text { mation } \\
\text { No. }\end{array}$} & \multicolumn{2}{|c|}{$\beta(1 \rightarrow 4)$} & \multicolumn{2}{|c|}{$\beta(1 \rightarrow 3)$} & \multirow{2}{*}{$\tau_{1}$} & \multirow{2}{*}{$\tau_{2}$} & \multicolumn{2}{|c|}{ Solution } & \multicolumn{2}{|c|}{ Free space } & \multicolumn{5}{|c|}{ Helical parameters } \\
\hline & $\theta_{1}$ & $\theta_{2}$ & $\theta_{3}$ & $\theta_{4}$ & & & Energy & Prob. & Energy & yrob. & $r$ & $d$ & $\rho$ & $C$ & $l_{0}$ \\
\hline 1 & 78 & 28 & 86 & 40 & 158 & 163 & 0 & 75.9 & 0 & 41.6 & 6.0 & 0.7 & 86 & $\mathrm{R}$ & 8.6 \\
\hline 2 & 74 & 7 & 84 & 28 & 131 & 189 & 0.92 & 17.0 & 0.53 & 17.5 & 6.4 & 4.8 & 7.9 & $\mathbf{L}$ & 8.9 \\
\hline 3 & 50 & 6 & 80 & 48 & 175 & 159 & 2.52 & 1.3 & 0.90 & 9.6 & 4.5 & 3.9 & 5.8 & L & 8.4 \\
\hline 4 & 53 & 21 & 59 & 24 & 43 & 160 & 2.22 & 2.1 & 10.3 & 7.9 & 4.5 & 6.8 & 4.8 & $\mathbf{L}$ & 9.2 \\
\hline 5 & 57 & 8 & 359 & 314 & 40 & 150 & 3.83 & 0.2 & 1.47 & 3.8 & 2.1 & 10.0 & 0.6 & L & 10.1 \\
\hline 6 & 53 & 343 & 54 & 35 & 104 & 164 & 3.12 & 0.5 & 1.56 & 3.3 & 3.7 & 8.3 & 2.3 & L & 9.0 \\
\hline 7 & 74 & 349 & 27 & 326 & 122 & 146 & 4.47 & 0.1 & 1.60 & 3.1 & 2.5 & 10.0 & 0.6 & $\mathbf{L}$ & 10.1 \\
\hline 8 & 49 & 337 & 76 & 37 & 120 & 192 & 2.96 & 0.6 & 1.63 & 2.9 & 3.9 & 7.5 & 3.1 & L & 8.8 \\
\hline 9 & 59 & 354 & 81 & 28 & 140 & 145 & 3.44 & 0.3 & 1.80 & 2.2 & 4.8 & 6.3 & 4.7 & $\mathbf{L}$ & 8.9 \\
\hline 10 & 59 & 13 & 32 & 166 & 148 & 148 & 4.94 & 0.0 & 1.82 & 2.2 & 3.4 & 6.4 & 2.6 & $\mathbf{R}$ & 7.6 \\
\hline 11 & 38 & 301 & 88 & 350 & 116 & 210 & 4.47 & 0.1 & 1.94 & 1.8 & 2.5 & 9.4 & 1.0 & L & 9.6 \\
\hline 12 & 36 & 19 & 37 & 25 & 156 & 198 & 4.83 & 0.0 & 2.19 & 1.2 & 3.4 & 7.9 & 3.0 & L & 9.3 \\
\hline 13 & 72 & 349 & 87 & 39 & 174 & 190 & 2.72 & 0.9 & 2.30 & 1.0 & 5.9 & 5.3 & 6.7 & L & 8.6 \\
\hline 14 & 68 & 60 & 83 & 29 & 177 & 160 & 3.56 & 0.2 & 2.64 & 0.6 & 4.9 & 2.0 & 7.3 & $\mathbf{R}$ & 8.9 \\
\hline 15 & 73 & 345 & 49 & 3 & 226 & 208 & 6.1 & 0.0 & 2.8 & 0.4 & 3.6 & 9.6 & 0.6 & $\mathrm{~L}$ & 9.6 \\
\hline 16 & 79 & 359 & 81 & 41 & 38 & 172 & 3.2 & 0.4 & 2.9 & 0.4 & 6.6 & 4.1 & 8.3 & $\mathrm{~L}$ & 8.6 \\
\hline
\end{tabular}

long. The heptamer would not be allowed in this conformation, due to steric overlap of the first and last monomers. However, without inclusion of long range (with respect to the number of connecting backbone bonds) excluded volume effects, our model incorrectly predicts long runs of the "circular" conformation, which cannot occur. The free space model is somewhat more realistic in that the characteristic ratio is 1.7. This occurs because the "circular" form is only half as probable and several other conformational states are pos- sible. Still, a significant underestimation of the dimensions of this uncharged form of HA is seen.

In an attempt to alleviate this problem, the lowest energy conformation of the monomer was restricted from occurring more than five consecutive times in the 100-mer. This had little effect on the characteristic ratio. It was not until the lowest energy conformer for the monomer was restricted to no more than two adjacent monomers that the characteristic ratio rose above 1 (the value for a truly random polymer). This is a strange finding 


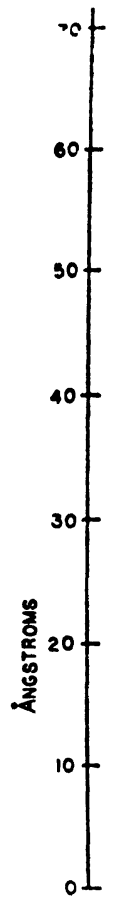

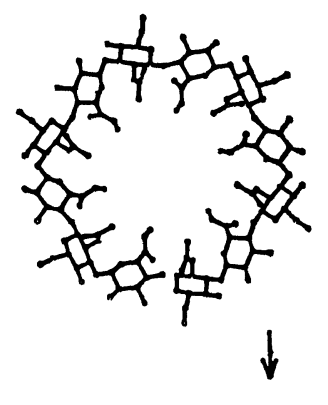
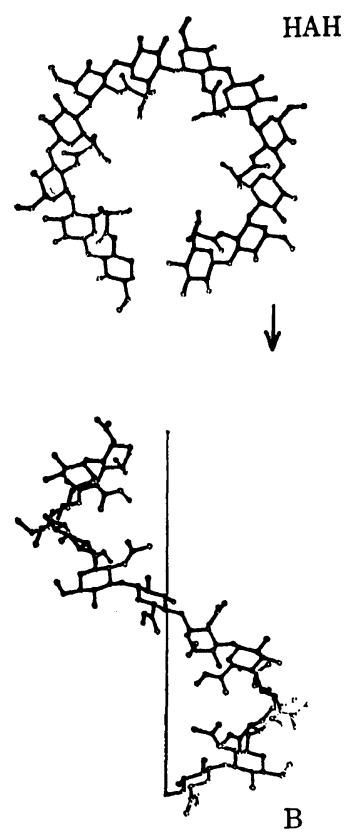

Figure 6. ORTEP drawings of two projections of the two most probable conformations for the HAH model. (a) corresponds to conformation No. 1 and (b) corresponds to conformation No. 2 of Tables V(A) and V(B). The scale in Ångstorms in shown.

which is not completely clear to us. We can conclude, however, that on total relaxation of the charge repulsions in HA, the polymer will collapse.

\section{DISCUSSION}

\section{Crystal Structures}

The chain conformations which we found to be the energetically most probable isolated nearestneighbor structures possess few structural similarities to observed and proposed X-ray diffraction models. Figure 10 illustrates the structures refined by Arnott's group. ${ }^{47,50}$ The energetics that we have calculated for these structures, shown in Table VIII, do not correspond even to near their energy minima. It would seem that intermolecular energetics, principally the ligand binding $\mathrm{COO}^{-}$ $\cdots \mathrm{Na}^{+}$complex interactions, water bridges, and the general optimization of close chain packing provide a stabilization for the crystal conformations that are not stable solely on an intramolecular basis.
In particular, the coordination complex $\left(\mathrm{COO}^{-}\right)$ .. $\mathrm{Na}^{+}$must act as a structural anchor point (see Figure 11). Crystal structure analysis of sodium formate ${ }^{70}$ and sodium oxylate ${ }^{71}$ indicate that there is a coordination of six oxygen atoms about a sodium ion, from five different molecules. These oxygen - sodium 'ligand' bonds are generally about $2.5 \AA$ in length. Semi-empirical potential energy functions have been derived from rare gas potential functions and refined to these two structures. $^{72}$ The strength of the $\mathrm{Na}^{+} \ldots \mathrm{O}$ bond is described as a function of charge and distance. For a +1 charge on the $\mathrm{Na}^{+} \mathrm{a}-0.5$ charge on the oxygen, the energy of this bond at $2.5 \AA$ is -57.0 $\mathrm{kcal} / \mathrm{mol}$. This would give an energy of -342 . $\mathrm{kcal} / \mathrm{mol}$ for the coordination of six oxygens. Our work using $\mathrm{CNDO} / 2$ on sodium acetate ${ }^{59}$ yielded correspondingly high stablizing energetics. If the charges of the sodium and oxygen are reduced to those predicted by $\mathrm{CNDO} / 2$ (to +0.639 and -0.470 respectively), the resulting energy is $-30.52 \mathrm{kcal} / \mathrm{mol}$ per bond and a complex energy 
of $-183.12 \mathrm{kcal} / \mathrm{mol}$. It is reasonable to suggest that formation of this complex in a crystal of HA could result in at least partially altering the preferential isolated $\mathrm{HA}^{-} \cdot \mathrm{Na}^{+}$chain conformations. In fact, the refined HA crystal structures both have a coordination about the sodium (see Figure 11). This coordination is not as strong as the sodium formate, since it includes hydroxyl and water oxygens at certain points. But the energy of these, using the reported empirical function, ${ }^{72}$ can be
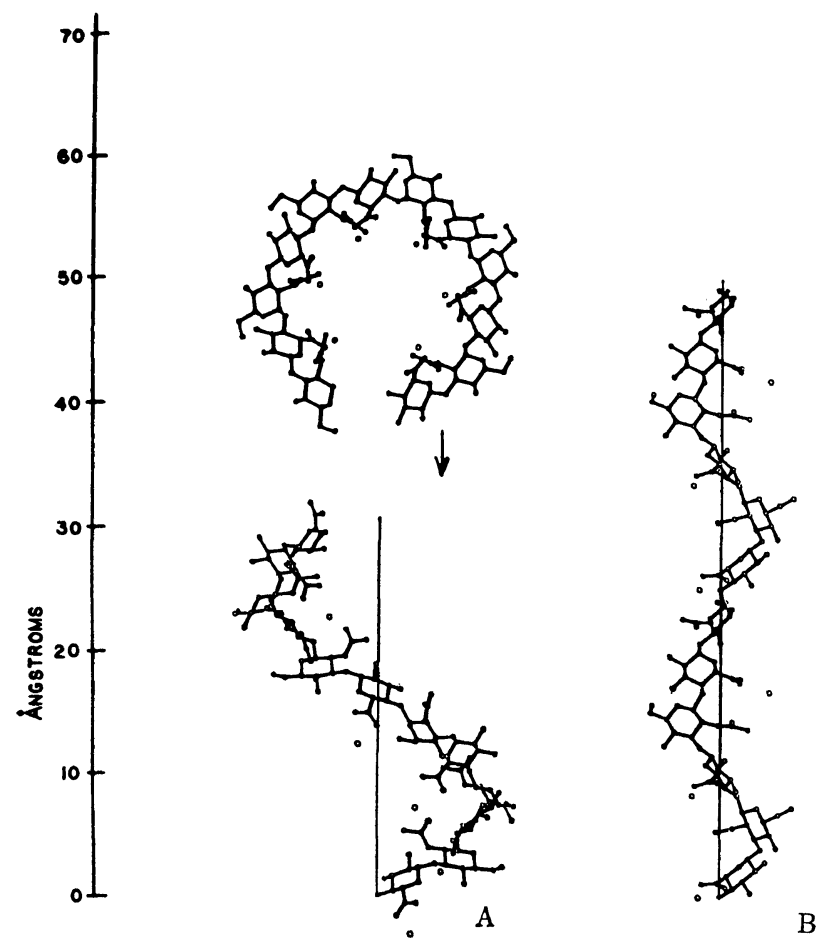

$\mathrm{HA}^{-} \cdot \mathrm{N}_{\mathrm{A}}^{+}$

Figure 7. ORTEP drawings of two projections of three conformations for the $\mathrm{HA}^{-} \cdot \mathrm{Na}^{+}$model. The sodium atom is drawn at its predicted location. (a) corresponds to the most probable solution conformation, conformation No. 1 in Table VI(A). (b) and (c) are the most probable free space conformations, Nos. 1 and 2, respectively in Table VI(B). The scale in Ångstroms is shown.

Table VI (A). Conformations of highest statistical weights for $\mathrm{HA}^{-} \cdot \mathrm{Na}^{+}$ (in solution). See text for a discussion

\begin{tabular}{|c|c|c|c|c|c|c|c|c|c|c|c|c|c|c|c|}
\hline \multirow{2}{*}{$\begin{array}{c}\text { Confor- } \\
\text { mation } \\
\text { No. }\end{array}$} & \multicolumn{2}{|c|}{$\beta(1 \rightarrow 4)$} & \multicolumn{2}{|c|}{$\beta(1 \rightarrow 3)$} & \multirow{2}{*}{$\tau_{1}$} & \multirow{2}{*}{$\tau_{2}$} & \multicolumn{2}{|c|}{ Solution } & \multicolumn{2}{|c|}{ Free space } & \multicolumn{5}{|c|}{ Helical parameters } \\
\hline & $\theta_{1}$ & $\theta_{2}$ & $\theta_{3}$ & $\theta_{4}$ & & & Energy & Prob. & Energy & Prob. & $r$ & $d$ & $\rho$ & $C$ & $l_{0}$ \\
\hline 1 & 77 & 9 & 75 & 32 & 111 & 165 & 0 & 89.1 & 3.16 & 0.3 & 6.5 & 5.0 & 7.9 & $\mathbf{L}$ & 8.9 \\
\hline 2 & 89 & 355 & 20 & 338 & 91 & 149 & 1.67 & 5.9 & 3.65 & 0.1 & 2.9 & 9.9 & 0.7 & $\mathbf{L}$ & 10.0 \\
\hline 3 & 67 & 7 & 86 & 33 & 71 & 168 & 2.29 & 2.2 & 2.61 & 0.8 & 5.7 & 4.2 & 7.3 & $\mathbf{L}$ & 8.8 \\
\hline 4 & 60 & 226 & 73 & 356 & 134 & 181 & 2.74 & 1.0 & 6.69 & 0.0 & 2.2 & 8.8 & 2.0 & $\mathbf{R}$ & 9.6 \\
\hline 5 & 111 & 354 & 329 & 346 & 92 & 187 & 3.45 & 0.3 & 6.39 & 0.0 & 2.4 & 9.3 & 1.4 & $\mathbf{L}$ & 9.7 \\
\hline 6 & 74 & 5 & 67 & 43 & 33 & 184 & 3.52 & 0.3 & 6.22 & 0.0 & 6.0 & 5.0 & 7.1 & $\mathbf{L}$ & 8.7 \\
\hline 7 & 70 & 356 & 13 & 322 & 121 & 169 & 3.65 & 0.2 & 4.26 & 0.1 & 2.3 & 10.0 & 0.5 & L & 10.1 \\
\hline 8 & 87 & 359 & 80 & 43 & 26 & 148 & 3.67 & 0.2 & 6.59 & 0.0 & 7.4 & 3.3 & 9.6 & $\mathbf{L}$ & 8.6 \\
\hline 9 & 58 & 231 & 78 & 42 & 193 & 159 & 3.74 & 0.2 & 8.02 & 0.0 & 2.4 & 8.4 & 1.0 & $\mathbf{L}$ & 8.6 \\
\hline 10 & 99 & 7 & 87 & 358 & 146 & 202 & 3.91 & 0.2 & 7.07 & 0.0 & 9.7 & 7.6 & 8.9 & $\mathbf{L}$ & 9.5 \\
\hline
\end{tabular}


Conformational Analysis of Glycosaminoglycans. III.

Table VI (B). Conformations of highest statistical weights for $\mathrm{HA}^{-} \cdot \mathrm{Na}^{+}$ (in free space). See text for a discussion

\begin{tabular}{|c|c|c|c|c|c|c|c|c|c|c|c|c|c|c|c|}
\hline \multirow{2}{*}{$\begin{array}{c}\text { Confor- } \\
\text { mation } \\
\text { No. }\end{array}$} & \multicolumn{2}{|c|}{$\beta(1 \rightarrow 4)$} & \multicolumn{2}{|c|}{$\beta(1 \rightarrow 3)$} & \multirow{2}{*}{$\tau_{1}$} & \multirow{2}{*}{$\tau_{2}$} & \multicolumn{2}{|c|}{ Solution } & \multicolumn{2}{|c|}{ Free space } & \multicolumn{5}{|c|}{ Helical parameters } \\
\hline & $\theta_{1}$ & $\theta_{2}$ & $\theta_{3}$ & $\theta_{4}$ & & & Energy & Prob. & Energ. & Prob & $r$ & $d$ & $\rho$ & $C$ & $l_{0}$ \\
\hline 1 & 32 & 319 & 65 & 41 & 209 & 196 & 10.67 & 0.0 & 0.0 & 53.5 & 3.0 & 8.3 & 1.7 & L & 8.8 \\
\hline 2 & 339 & 320 & 34 & 290 & 70 & 194 & 10.53 & 0.0 & 0.26 & 34.8 & 3.8 & 9.3 & 2.5 & $\mathbf{R}$ & 10.0 \\
\hline 3 & 39 & 14 & 62 & 38 & 131 & 175 & 19.04 & 1.43 & 1.00 & 5.2 & 4.8 & 7.7 & 4.6 & L & 8.9 \\
\hline 4 & 353 & 317 & 61 & 29 & 85 & 198 & 12.7 & 0.0 & 1.73 & 3.2 & 2.2 & 8.4 & 1.8 & L & 9.1 \\
\hline 5 & 19 & 314 & 19 & 301 & 120 & 1.4 & 14.58 & 0.0 & 2.17 & 1.6 & 3.1 & 9.9 & 1.1 & $\mathbf{R}$ & 10.1 \\
\hline 6 & 67 & 7 & 86 & 33 & 71 & 168 & 2.29 & 2.2 & 2.61 & 0.8 & 8.0 & 6.0 & 9.7 & $\mathrm{~L}$ & 8.8 \\
\hline 7 & 51 & 5 & 77 & 45 & 37 & 179 & 15.48 & 0.0 & 2.99 & 0.4 & 4.5 & 4.6 & 5.6 & $\mathrm{~L}$ & 8.5 \\
\hline
\end{tabular}

Table VII. Calculated chain properties for the three forms of HA

\begin{tabular}{|c|c|c|c|c|c|c|c|}
\hline & & \multicolumn{2}{|c|}{$\mathrm{HA}^{-}$} & \multicolumn{2}{|c|}{$\mathrm{HAH}$} & \multicolumn{2}{|c|}{$\mathrm{HA}^{-} \cdot \mathrm{Na}^{+}$} \\
\hline & & Solution & Free space & Solution & Free space & Solution & Free space \\
\hline \multirow{3}{*}{$\begin{array}{l}50 \text {-mer } \\
\mathrm{MW}=1.66 \times 10^{4}\end{array}$} & $\left\langle r_{0}^{2}\right\rangle^{(a)}$ & $1.82 \times 10^{5}$ & $1.80 \times 10^{5}$ & $1.04 \times 10^{3}$ & $6.69 \times 10^{3}$ & $3.24 \times 10^{4}$ & $5.71 \times 10^{4}$ \\
\hline & $\sigma\left\langle r_{0}^{2}\right\rangle^{(\mathrm{b})}$ & 225.8 & 276.0 & 60.0 & 142.0 & 265.0 & 408.0 \\
\hline & $C_{50}(\mathrm{c})$ & 43.18 & 40.83 & 0.30 & 1.72 & 8.05 & 13.48 \\
\hline \multirow{3}{*}{$\begin{array}{l}100 \text {-mer } \\
\mathrm{MW}=3.32 \times 10^{4}\end{array}$} & $\left\langle r_{0}^{2}\right\rangle$ & $6.61 \times 10^{5}$ & $6.33 \times 10^{5}$ & $2.11 \times 10^{3}$ & $1.31 \times 10^{4}$ & $7.53 \times 10^{4}$ & $1.31 \times 10^{5}$ \\
\hline & $\sigma\left\langle r_{0}{ }^{2}\right\rangle$ & 590.5 & 667.0 & 90.0 & 207.0 & 452.0 & 579.0 \\
\hline & $C_{100}$ & 78.39 & 71.70 & 0.30 & 1.68 & 9.38 & 15.41 \\
\hline \multirow{3}{*}{$\begin{array}{l}200 \text {-mer } \\
M W=6.64 \times 10^{4}\end{array}$} & $\left\langle r_{0}^{2}\right\rangle$ & $2.25 \times 10^{8}$ & $1.96 \times 10^{8}$ & $4.47 \times 10^{3}$ & $2.66 \times 10^{4}$ & $1.73 \times 10^{5}$ & $2.65 \times 10^{5}$ \\
\hline & $\sigma\left\langle r_{0}{ }^{2}\right\rangle$ & 1373.5 & 1497.0 & 127.0 & 304.0 & 715.0 & 912.0 \\
\hline & $C_{200}$ & 133.4 & 111.25 & 0.29 & 1.71 & 10.75 & 15.62 \\
\hline \multirow{3}{*}{$\begin{array}{l}300 \text {-mer } \\
\mathrm{MW}=9.96 \times 10^{4}\end{array}$} & $\left\langle r_{0}^{2}\right\rangle$ & $4.37 \times 10^{8}$ & $3.65 \times 10^{8}$ & $6.48 \times 10^{3}$ & $3.96 \times 10^{4}$ & $1.94 \times 10^{5}$ & $4.16 \times 10^{5}$ \\
\hline & $\sigma\left\langle r_{0}^{2}\right\rangle$ & 2245.0 & 2363.0 & 145.0 & 355.0 & 849.0 & 1145.0 \\
\hline & $C_{300}$ & 173.02 & 138.25 & 0.29 & 1.70 & 10.33 & 16.33 \\
\hline \multirow{3}{*}{$\begin{array}{l}500 \text {-mer } \\
\mathrm{MW}=9.96 \times 10^{4}\end{array}$} & $\left\langle r_{0}^{2}\right\rangle$ & $9.59 \times 10^{8}$ & $7.51 \times 10^{8}$ & $1.15 \times 10^{4}$ & $6.56 \times 10^{4}$ & $4.72 \times 10^{5}$ & $6.90 \times 10^{5}$ \\
\hline & $\sigma\left\langle r_{0}^{2}\right\rangle$ & 3873.0 & 3796.0 & 218.0 & & 1203.0 & 1423.0 \\
\hline & $C_{500}$ & 227.28 & 170.48 & 0.30 & 1.69 & 11.70 & 16.26 \\
\hline \multirow{3}{*}{$\begin{array}{l}750 \text {-mer } \\
\mathrm{MW}=2.49 \times 10^{5}\end{array}$} & $\left\langle r_{0}^{2}\right\rangle$ & $1.73 \times 10^{7}$ & $1.19 \times 10^{7}$ & $1.54 \times 10^{4}$ & $9.94 \times 10^{4}$ & $6.36 \times 10^{5}$ & $9.89 \times 10^{5}$ \\
\hline & $\sigma\left\langle r_{0}^{2}\right\rangle$ & 566.6 & 5237.0 & 215.0 & 562.0 & 1379.0 & 1778.0 \\
\hline & $C_{750}$ & 273.28 & 179.80 & 0.27 & 1.70 & 10.53 & 15.54 \\
\hline \multirow{3}{*}{$\begin{array}{l}1000-\mathrm{mer} \\
\mathrm{MW}=3.32 \times 10^{5}\end{array}$} & $\left\langle r_{0}^{2}\right\rangle$ & $2.45 \times 10^{7}$ & $1.70 \times 10^{7}$ & $2.13 \times 10^{4}$ & $1.40 \times 10^{5}$ & $8.84 \times 10^{5}$ & $1.38 \times 10^{8}$ \\
\hline & $\sigma\left\langle r_{0}^{2}\right\rangle$ & 7202.0 & 5543.0 & 262.0 & 677.0 & 1732.0 & 1088.0 \\
\hline & $C_{1000}$ & 291.20 & 192.80 & 0.30 & 1.81 & 10.98 & 16.29 \\
\hline \multirow{3}{*}{$\begin{array}{l}1500 \text {-mer } \\
\mathrm{MW}=4.98 \times 10^{5}\end{array}$} & $\left\langle r_{0}^{2}\right\rangle$ & $3.60 \times 10^{7}$ & $2.48 \times 10^{7}$ & $3.18 \times 10^{4}$ & $2.18 \times 10^{5}$ & $1.36 \times 10^{8}$ & $2.15 \times 10^{6}$ \\
\hline & $\sigma\left\langle r_{0}^{2}\right\rangle$ & 9941.0 & 8524.0 & 150.0 & 847.0 & 2116.0 & 1227.0 \\
\hline & $C_{1500}$ & 285.13 & 187.58 & 0.28 & 1.87 & 11.25 & 16.88 \\
\hline \multirow{3}{*}{$\begin{array}{l}\text { 2000-mer } \\
\mathrm{MW}=6.64 \times 10^{5}\end{array}$} & $\left\langle r_{0}^{2}\right\rangle$ & $5.23 \times 10^{7}$ & $3.67 \times 10^{7}$ & $4.20 \times 10^{4}$ & $2.73 \times 10^{5}$ & $1.82 \times 10^{8}$ & $2.86 \times 10^{6}$ \\
\hline & $\sigma\left\langle r_{0}^{2}\right\rangle$ & 12306.0 & 10060.0 & 371.0 & 923.0 & 2393.0 & 2949.0 \\
\hline & $C_{2000}$ & 310.33 & 203.55 & 0.28 & 1.75 & 11.28 & 16.83 \\
\hline
\end{tabular}

a Average mean square end-to-end distance in $\AA^{2}{ }^{2}$ b Standard deviation found for $\left\langle r_{0}^{2}\right\rangle$. c Characteristic ratio. 

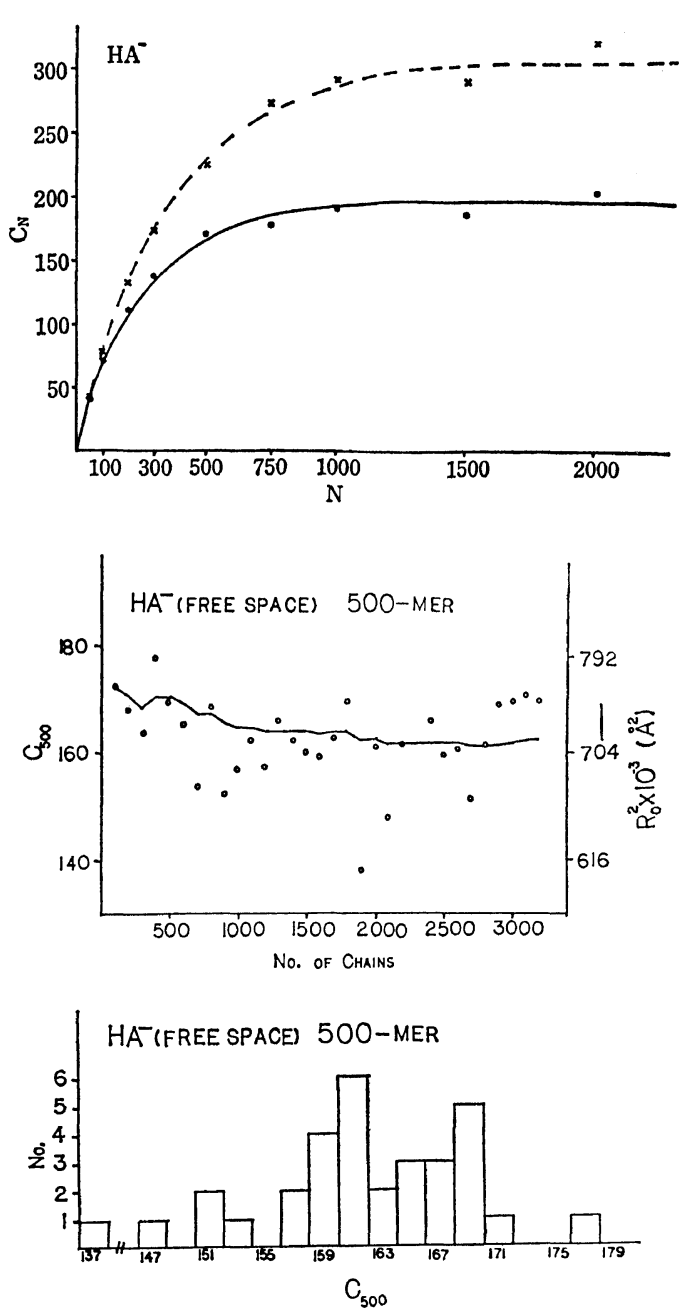

Figure 8. Chain statistics for model $\mathrm{HA}^{-}: \times$, solution; $\bigcirc$, free space. (a) characteristic ratio, $C_{n}$, is plotted against $n$ (see eq 7). (b) characteristic ratios of a 500 -mer $\left(C_{500}\right)$ for every 50 chains sampled are plotted as (0). The average $C_{500}$ for all the chains sampled is plotted as the line. (c) the distribution of $C_{800}$ is shown for the data in (b).

calculated. Assuming the charges for the sodium and carboxyl oxygen are those reported above, and -0.25 for the hydroxyl and water oxygen charges, the energy of the coordination complex is $-158.93 \mathrm{kcal} / \mathrm{mol}$ for the four-fold tetragonal structure $^{50}-97.41 \mathrm{kcal} / \mathrm{mol}$ for the four-fold orthorhombic structure, ${ }^{50}$ and $-100.82 \mathrm{kcal} / \mathrm{mol}$ for the three-fold structure. ${ }^{47}$ This compares to a value of $-63.28 \mathrm{kcal} / \mathrm{mol}$ for our isolated chain model with only two 'ligand' bonds to the carboxyl

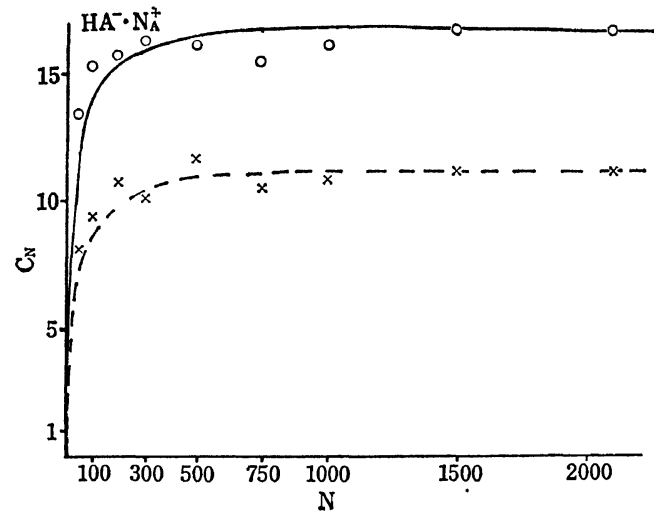

Figure 9. Chain statistics for model $\mathrm{HA}^{-} \cdot \mathrm{Na}^{+}: \times$, solution; $O$, free space. The characteristic ratio, $C_{\mathrm{N}}$, is plotted against $\boldsymbol{n}$ (see eq 7).

oxygens of one saccharide unit and the sodium ion held rigid, as described earlier. These results are summarized in Table IX. The excess energy of coordination easily compensates for the conformational energy differences. The biological significance of these $\mathrm{HA}^{-} \cdot \mathrm{Na}^{+}$crystal structures, consequently, may depend upon nature's propensity to build the coordination complexes into connective tissue.

\section{Hydrodynamic Properties}

We have compared our data to mean square endto-end distance, $\left\langle\boldsymbol{R}_{0}{ }^{2}\right\rangle$, solution measurements. The results are plotted in Figure 12. Five physicochemical states are given $\left(\mathrm{HA}^{-}\right.$in solution and free space; $\mathrm{HA}^{-} \cdot \mathrm{Na}^{+}$in solution and free space; and HAH in free space) on a $\log _{10}-\log _{10}$ plot of $\left\langle R_{0}^{2}\right\rangle$ vs. molecular weight, MW. A few qualitative conclustions can be drawn from an inspection of this plot. $\mathrm{HA}^{-}$becomes more extended when the solution energy term is included, but only by a small amount. $\mathrm{HA}^{-} \cdot \mathrm{Na}^{+}$shows the expected contraction upon solvation. The most significant observation is that these results are in reasonable qualitative agreement with experimental observations of $\mathrm{HA}$ in solution. The polymer expands at low ionic strength $\left(\mathrm{HA}^{-} \cdot \mathrm{Na}^{+}\right.$to $\left.\mathrm{HA}^{-}\right)$and high $\mathrm{pH}$ (HAH to $\left.\mathrm{HA}^{-}\right){ }^{10,13,25}$

Quantitative correspondence of our predictions can also be seen in Figure 12. End-to-end distance data and radius of gyration data $\left(\left\langle S_{0}{ }^{2}\right\rangle=1 / 6\right.$ $\left.\left\langle R_{0}{ }^{2}\right\rangle\right)$ by various authors have been reported and are listed in Table X. Early data by Blix and Snellman ${ }^{4}$ falls along the $\mathrm{HA}^{-}$curve. However, 

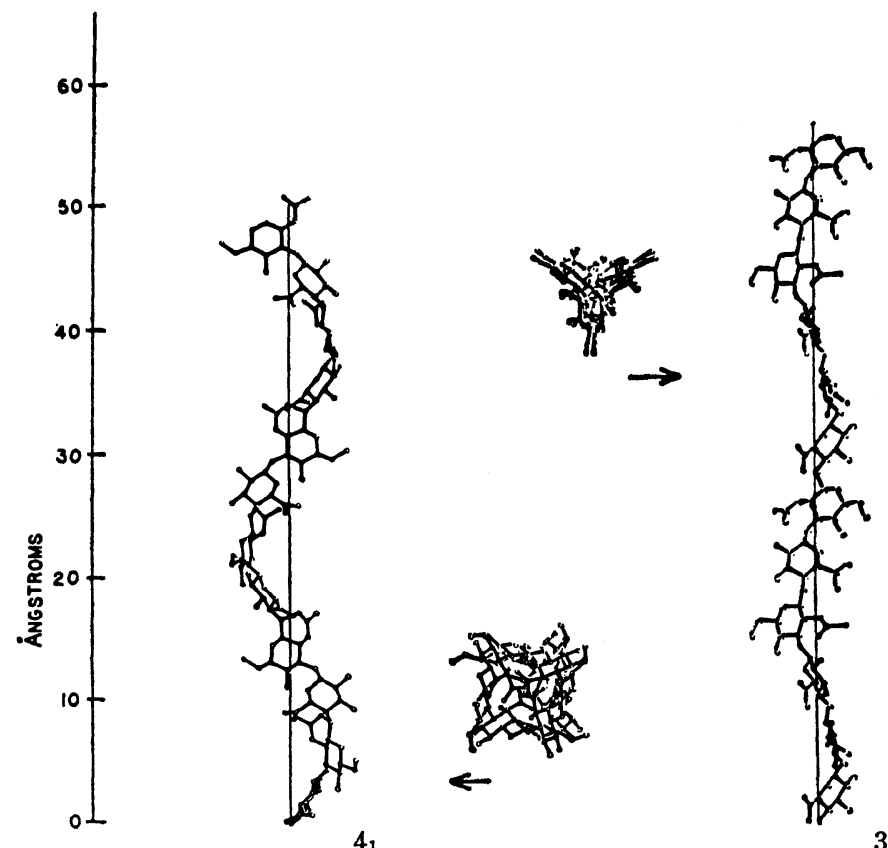

Figure 10. ORTEP drawings of two projections of the two refined sodium hyaluronate crystal structures. $^{47,50}$ See text and Table VIII. Scale in Ångstroms is shown.

Table VIII. Energy in $\mathrm{kcal} / \mathrm{mol}$ of each model for the refined crystal structure conformations of HA

\begin{tabular}{|c|c|c|c|c|c|c|}
\hline \multirow{2}{*}{ Crystal structure } & \multicolumn{2}{|c|}{$\mathrm{HA}^{-}$} & \multicolumn{2}{|c|}{$\mathrm{HAH}$} & \multicolumn{2}{|c|}{$\mathrm{HA}^{-} \cdot \mathrm{Na}^{+}$} \\
\hline & Solution & Free space & Solution & Free space & Solution & Free space \\
\hline $\begin{array}{l}\text { 3-Fold helix } \\
\text { (ref 50) }\end{array}$ & 5.08 & 3.31 & 7.93 & 4.57 & $\begin{array}{c}42.15 \\
(17.53)^{\mathrm{a}}\end{array}$ & $\begin{array}{l}32.53 \\
(8.34)^{\mathrm{a}}\end{array}$ \\
\hline $\begin{array}{l}\text { 4-Fold helix } \\
\text { (ref 47) }\end{array}$ & 9.53 & 7.74 & 7.09 & 3.69 & $\begin{array}{c}12.59 \\
(10.90)^{\mathrm{a}}\end{array}$ & $\begin{array}{c}5.74 \\
(4.27)^{\mathrm{a}}\end{array}$ \\
\hline
\end{tabular}

a These energies were obtained by performing bond rotations on the pendent groups ( $\tau$-rotations) to minimize the conformational energy.

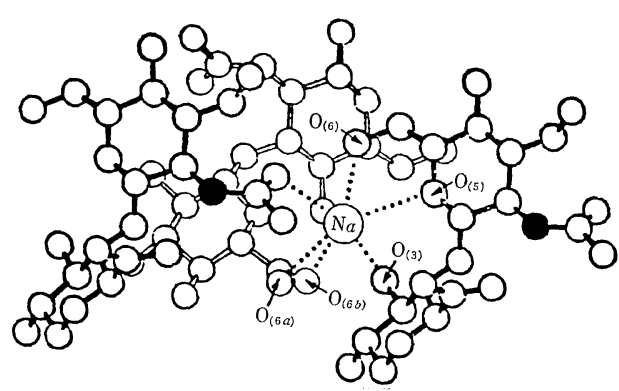

Figure 11. For the refined crystal structure of a fourfold sodium hyaluronate the sodium atom coordination is shown; (taken from reference 50),
Table IX. Sodium coordination energy

\begin{tabular}{lcr}
\hline \multicolumn{1}{c}{ Conformation } & $\begin{array}{c}\text { Number of } \\
\text { oxygen atoms } \\
\text { coordinated }\end{array}$ & Energy $^{\mathrm{a}}$ \\
\hline $4_{1}$ Tetragonal $^{\mathrm{b}}$ & 6 & $-158.9 \mathrm{kcal} / \mathrm{mol}$ \\
$4_{2}$ Orthorhombic $^{\mathrm{b}}$ & 6 & $-97.4 \mathrm{kcal} / \mathrm{mol}$ \\
$3_{3}{ }^{\mathrm{c}}$ & 6 & $-100.8 \mathrm{kcal} / \mathrm{mol}$ \\
Our fixed geometry & 2 & $-63.3 \mathrm{kcal} / \mathrm{mol}$ \\
\hline${ }^{a}$ Empirical potential function refined for sodium \\
$\quad$ formate and sodium oxalate crystal structures \\
reported in ref 72. \\
b Reference 50. \\
' Reference 47.
\end{tabular}




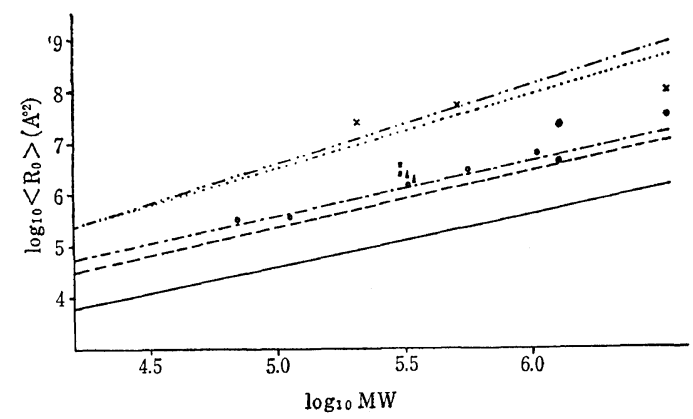

Figure 12. Straight line least-squares fit of $\log _{10}(\mathrm{MW})$ vs. $\log _{10}\left(\left\langle R_{0}^{2}\right\rangle\right)$ for five of our models: $\times$, Blix and Snellman $;{ }^{4,32} \bigcirc$, Cleland and Wang $;^{17} \triangle$, Cleland $;^{25}$ -, Rowen, Brunish, and Bishop. ${ }^{13}$ Also plotted are data as shown in Table $\mathrm{X}$. - - - , $\mathrm{HA}^{-}$solution; -.--.-., $\mathrm{HA}^{-}$free space; -----, $\mathrm{HA}^{-} \mathrm{NA}^{+}$solution; $-\mathrm{HA}^{-} \mathrm{NA}^{+}$free space; —_, $\mathrm{HAH}_{-}$free space.

their samples quite probably contained protein contaminants and the agreement may be fortuitous. The results of Cleland and Wang ${ }^{17}$ at an ionic strength of 0.5 fall, as expected, along the $\mathrm{HA}^{-}$. $\mathrm{Na}^{+}$curve. It can be seen in Table $\mathrm{X}$ that the free space predictions of $\left\langle S_{0}^{2}\right\rangle$ for $\mathrm{HA}^{-} \cdot \mathrm{Na}^{+}$is within $10 \%$ of the Cleland and Wang ${ }^{17}$ data. The aqueous solution predictions of $\left\langle S_{0}{ }^{2}\right\rangle$ are not quite as good, but generally within $30 \%$ of the reported experimental values. Almost all the predicted values are higher than those measured, suggesting that the strengths of the charge repulsions chosen in our calculations are slightly too large. The comparsion between theoretical and measured $\left\langle S_{0}{ }^{2}\right\rangle$ 's also suggests that the solvation shell model for the sodium ion may need further refinement: e.g., either the hydration shell of the sodium ion and/or the energy for water exclusion, $\Delta f$, may be too large. Nevertheless, the agreement is reasonably good.

The reasonableness of the predicted effects of ionic strength variation can be evaluated using the data of Cleland ${ }^{25}$ and Rowen. ${ }^{13}$ Their data for high ionic strength solutions of HA $(0.5$ and 0.3 respectively) lie along our $\mathrm{HA}^{-} \cdot \mathrm{Na}^{+}$curve. The predicted increase in $\left\langle R_{0}{ }^{2}\right\rangle$ for the low ionic strength samples $(\mu=0.01)$ is experimentally observed, but not to the degree suggested by the calculations. Cleland ${ }^{25}$ also reports little difference between the high salt and the low $\mathrm{pH}$ dimensions.

\section{CONCLUSIONS}

It is to be emphasized that the calculations are based upon an idealized model which approxi-

Table X. A comparison of theoretical (as predicted from conformational analyses) and experimental radii of gyration for $\mathrm{HA}^{-} \cdot \mathrm{Na}^{+}$. See Figure 11 and text for additional details of this comparison

\begin{tabular}{|c|c|c|c|c|c|c|c|c|}
\hline \multirow{3}{*}{\multicolumn{2}{|c|}{$\begin{array}{c}\text { Molecular } \\
\text { weight } \\
\times 10^{6}\end{array}$}} & \multicolumn{4}{|c|}{ Theoretical } & \multicolumn{3}{|c|}{ Experimental } \\
\hline & & \multicolumn{2}{|c|}{$\mathrm{HA}^{-} \cdot \mathrm{Na}^{+}$(solution) } & \multicolumn{2}{|c|}{$\mathrm{HA}^{-} \cdot \mathrm{Na}^{+}$(free space) } & \multirow{2}{*}{$\left\langle S^{2}\right\rangle^{1 / 2}$} & \multirow{2}{*}{ Ionic strength } & \multirow{2}{*}{ Reference } \\
\hline & & Predicted & Error, \% & Predicted & Error, \% & & & \\
\hline 1. & 3.400 & 1320.6 & 67.65 & 1594.2 & 60.95 & 4082.5 & & \\
\hline 2. & 0.500 & 466.8 & 83.67 & 583.5 & 79.55 & 2857.7 & & \\
\hline 3. & 0.200 & 283.9 & 85.51 & 361.8 & 81.54 & 1959.6 & & 4 and 32 \\
\hline 4. & 0.069 & 159.4 & 30.10 & 207.3 & 9.09 & 228 & 0.5 & \\
\hline 5. & 0.110 & 205.3 & 16.56 & 264.6 & -7.55 & 246 & 0.5 & \\
\hline 6. & 0.320 & 366.4 & 23.67 & 462.7 & 3.60 & 480 & 0.5 & 17 \\
\hline 7. & 0.550 & 491.5 & 27.72 & 614.4 & 9.65 & 680 & 0.5 & \\
\hline 8. & 1.030 & 690.9 & 29.86 & 853.2 & 13.38 & 985 & 0.5 & \\
\hline 9. & 3.400 & 1320.6 & 44.97 & 1594.2 & 33.57 & 2400 & 0.5 & \\
\hline 10 . & 0.300 & 353.8 & 53.33 & 447.3 & 40.98 & 758 & 0.01 & \\
\hline 11. & 0.300 & 353.8 & 42.76 & 447.3 & 27.62 & 618 & 0.5 & \\
\hline 12. & 0.320 & 366.4 & 37.69 & 462.7 & 21.31 & 588 & $(0.01 \mathrm{HCl})$ & 25 \\
\hline 13. & 0.340 & 378.6 & 27.47 & 477.6 & 8.50 & 522 & $(1.0 \mathrm{HCl})$ & \\
\hline 14. & 1.270 & 774.0 & 7.86 & 952.1 & -13.34 & 840 & 0.3 & 13 \\
\hline 15. & 1.270 & 774.0 & 59.26 & 952.1 & 49.89 & 1900 & 0 & \\
\hline
\end{tabular}


mates only the nearest neighbor interactions of the HA polymer in three physicochemical states. These represent limiting end points in ionic strength and $\mathrm{pH}$ titrations and, as such, probably are never completely realized. The influences of both ionic and polymeric species dictate the precise physicochemical state of the actual disaccharide. Comparison of our results with the solution work on HA suggests the following: (A) The model of $\mathrm{HA}^{-}$. $\mathrm{Na}^{+}$seems to do a good job in approximating the actual charge shielding of the carboxyl groups which occurs in solution. (B) We overestimate the charge repulsions seen by the low ionic strength polymer, $\mathrm{HA}^{-}$. This is certainly understandable since there can never really be a totally unshielded charge interaction, as we have allowed in $\mathrm{HA}^{-}$. Counter-ions are present in solutions containing the low ionic strength polymer and there is probably some association (to a lesser degree than the high ionic strength solutions). (C) Our HAH model appears to grossly underestimate the low $\mathrm{pH}$ polymer dimensions. This could be an indication that, even at the lower $\mathrm{pH}$ values, the polymer remains partially charged. A totally uncharged polymer in dilute solution should be much more collapsed. (D) On the basis of the qualitative agreement between theory and experiment given in Figure 12, two conflicting molecular pictures of $\mathrm{HA}$ in
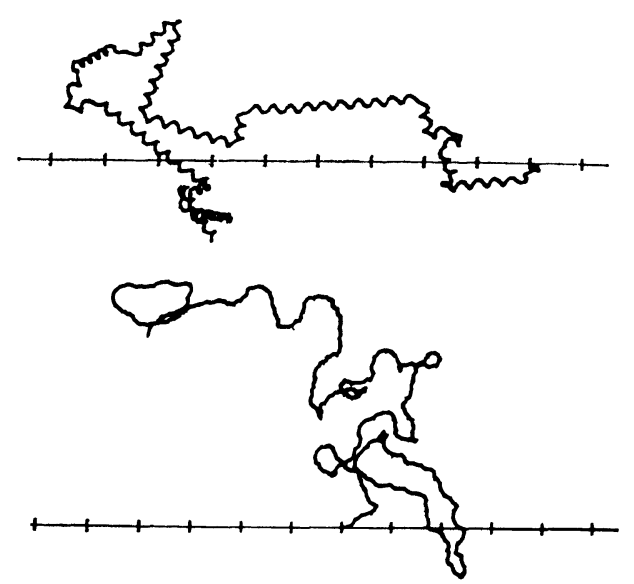

Figure 13. Computer generated picture of HA polymer using the $\mathrm{HA}^{-} \cdot \mathrm{Na}^{+}$statisties: (A) solution model; (B) free space model. Only the backbone virtual bonds (connecting consecutive $\beta(1 \rightarrow 4)$ oxygens) are drawn. (Tick marks are placed at 100 Ångstrom intervals.) solution emerge. Refer to Figure 13 for drawings of representitive computer-generated polymers (A for solution and B for free space). $\mathrm{HA}^{-} \cdot \mathrm{Na}^{+}$ (solution statistics) suggests a model with one predominant conformation along the polymer backbone. This conformation occurs, on the average, over ten consecutive disaccharides (50 ̊ segments). However, considerably longer and shorter runs occur frequently. The free space model is quite different. The most probable conformation persists for very short (two to three) adjacent disaccharide repeats. These are most frequently alternated with the second most probable disaccharide conformation. This second model gives the better overall agreement to experimental results. Neither of these two models is in agreement with the model from the aqueous NMR studies discussed earlier. ${ }^{41}$ The persistance of sixty disaccharide units in "stiff segments" is not predicted by our work. However, the NMR study suggests that there are covalent links holding these large (approximately 20,000 MW) segments rigid. These covalent links are unidentified and consequently could not be incorporated in our model.

Acknowledgement. This work was supported, in part, by a grant (No. AM-17110-07) from the National Institute of Arthritis and Metabolic Diseases, U.S. Public Health Service. A. J. Hopfinger is a Sloan Research Fellow. We also would like to acknowledge computing facilities made available to us at NIH by Dr. G. W. Milne and at EPA by Dr. S. Heller.

\section{REFERENCES}

1. A. J. Hopfinger, "Intermolecular Interactions and Biomolecular Organization," Wiley-Interscience, New York, N.Y., 1977, p 395

2. K. Meyer and J. W. Palmer, J. Biol. Chem., 107, 629-634 (1934).

3. K. Meyer, Physiol. Rev., 27, 335 (1947).

4. G. Blix and O. Snellman, Arkiv Kemi Mineral. Geol., 19A, 1-19 (1945).

5. T. C. Laurent, "Physico-Chemical Studies on Hyaluronic Acid," Almquist and Wilsell, Upsula, 1957.

6. E. A. Balazs, Fed. Proceed., 17, 1086-1092 (1958).

7. B. S. Blumberg and A. G. Ogston, "Ciba Foundation Symposium on Chemistry and Biology of Mucopolysaccharides," Churchill, London, 1958, pp 22-41. 
8. H. J. Rogers, Biochemical Society Symposia, No. 20, 51 (1960).

9. E. A. Balazs and R. W. Jeanloz, "The Amino Sugars," Vol. II-A, Academic Press, New York, N.Y., 1965.

10. T. C. Laurent, "The Chemistry and Molecular Biology of the Interstitial," Academic Press, New York, N.Y., 1969, pp 703-732.

11. B. S. Blumberg and G. Oster, Science, 120, 432433 (1954).

12. T. C. Laurent and J. Gergely, J. Biol. Chem., 212, 325-333 (1955).

13. J. Rowen, R. Brunish, and F. W. Bishop, Biochem. Biophys. Acta, 19, 480-489 (1956).

14. T. C. Laurent, M. Ryan, and A. Pietruszkiewicz, ibid., 42, 476-485 (1960).

15. B. N. Preston, M. Davies, and A. G. Ogston, Biochem. J., 96, 449-474 (1965).

16. E. A. Balazs, D. Watson, I. F. Ruff, and S. Roseman, Arthrit. Rheum, 10, 357 (1967).

17. R. L. Cleland and J. L. Wang, Biopolymers, 9, 799-810 (1970).

18. D. A. Swann, Biochim. Biophys. Acta, 156, 17-30 (1968).

19. T. A. Mashburn, P. Hoffman, and D. Hsu, ibid., 362, 366-374 (1974).

20. B. S. Blumberg, A. G. Ogston, D. A. Lowther, and H. J. Rogers, Biochem. J., (1958).

21. E. A. Balazs, Fed. Proceed., 25, 1817-1822 (1966).

22. J. A. Christiansen and C. E. Jensen, Acta Chem. Scand, 7, 1247 (1953).

23. A. G. Ogston and J. E. Stanier, Biochem. J., 49, 585-590 (1951).

24. A. G. Ogston, and J. E. Stainer, Disc. Faraday Soc., 13, 275 (1953).

25. R. L. Cleland, Biopolymers, 8, 1519-1529 (1968).

26. L. Varga, J. Biol. Chem., 217, 652-658 (1955).

27. E. A. Balazs and T. C. Laurent, J. Polym. Sci., 6, 665 (1951).

28. T. C. Laurent, J. Biol. Chem., 216, 263 (1955).

29. B. S. Blumberg, G. Oster, and K. Meyer, J. Clin. Investig., 34, 1454 (1955).

30. A. L. Stone, Biopolymers, 3, 617-624 (1965).

31. A. L. Stone, ibid., 7, 173-188 (1969a).

32. A. L. Stone, in "Structure and Stability of Biological Macromolecules," Vol. 2, S. N. Trimnsheff and G. O. Fasman, Eds., Marcel Dekker, New York, N.Y., p 353.

33. A. L. Stone, Biopolymers, 10, 739-751 (1971).

34. A. L. Stone, ibid., 11, 2625-2631 (1972).

35. B. Chakrabarti and E. A. Balazs, J. Mol. Biol., 78, 135-141 (1973a).

36. B. Chakrabarti and E. A. Balazs, Biochem. Biophys. Res. Commun., 52, 1170-1176 (1973b).
37. S. Hirano and S. Kono-Ikeda, Biopolymers, 13, 1357-1366 (1974).

38. J. J. Cael, Ph.D. Dissertation, Department of Macromolecular Science, Case Western Reserve University, Cleveland Ohio, 1975.

39. T. W. Barrett, Biochim. Biophys. Acta, 385, 157161 (1975).

40. T. W. Barrett, Physiol. Chem. \& Phys., 8, 125-130 (1976).

41. A. Darke, E. G. Finer, R. Moorhouse, and D. A. Rees, J. Mol. Biol., 99, 477-486 (1975).

42. C. E. Jenner and F. Carlson, Acta Chem. Scand., 8, 1357 (1954).

43. J. H. Fessler and L. I. Fessler, Biochemistry, 55, 141-147 (1966).

44. E. D. T. Atkins, C. F. Phelps, and J. K. Sheehan, Biochem. J., 128, 1255-1263 (1972).

45. E. D. T. Atkins and J. K. Sheehan, Nature New Biology, 235, 253-256 (1972).

46. J. K. Sheehan, E. D. T. Atkins, and I. A. Nieduszynski, J. Mol. Biol., 91, 153-163 (1975).

47. W. C. Winter, P. J. C. Smith, and S. Arnott, J. Mol. Biol., 99, 219-235 (1975).

48. I. Dea, R. Moorhouse, D. A. Rees, S. Arnott, T. J. Guss, and E. A. Balazs, Science, 179, 560562 (1973).

49. E. D. T. Atkins and J. K. Sheehan, Science, 179, 562-564 (1973).

50. J. M. Guss, D. W. L. Hukins, P. J. C. Smith, W. C. Winter, S. Arnott, R. Moorhouse, and D. A. Rees, J. Mol. Biol., 95, 359-384 (1975).

51. D. A. Rees, J. Chem. Soc., B, 217-226 (1969).

52. R. L. Cleland, Biopolymers, 10, 1925-1948 (1971).

53. H. J. R. Weintraub and A. J. Hopfinger, Int. J. Quant. Chem., Quantum Bio. Symp., No. 2, 203208 (1975).

54. R. Potenzone, E. Cavicchi, H. J. R. Weintraub, and A. J. Hopfinger, Computers in Chemistry, 1, 187-194 (1977).

55. A. J. Hopfinger, "Conformational Properties of Macromolecules," Academic Press, New York, N.Y., 1973, p 339.

56. J. A. Pople and D. L. Beveridge, "Approximate Molecular Orbital Theory," McGraw Hill, New York, N.Y., 1970, p 214.

57. R. Potenzone and A. J. Hopfinger Carb. Res., 40, 323-336 (1975).

58. R. Potenzone and A. J. Hopfinger, ibid, 46, 67-73 (1976).

59. K. Forsythe, R. Potenzone, and A. J. Hopfinger, in preparation (1977).

60. K. A. Mauritz, E. Baer, and A. J. Hopfinger, J. Polym. Sci., 12, 2185-2197 (1973).

61. K. A. Mauritz and A. J. Hopfinger, J. Polym. Sci., 
Conformational Analysis of Glycosaminoglycans. III.

13, 787-798 (1975).

62. S. H. Kim and B. T. Rubin, J. Phys. Chem., 77, 1245-1250 (1973).

63. F. T. Hesselink, T. Ooi, and H. A. Scheraga, Macromolecules, 6, 541-552 (1973).

64. S. Rao and W. G. Miller, Biopolymers, 12, 834 843 (1973).

65. W. C. Davidon, AEC Res. and Dev. Report No. ANL-5090 (1959).

66. K. D. Gibson and H. A. Scheraga, Proc. Nat. Acad. Sci., 58, 1317-1323 (1967).

67. H. Sugeta and J. Miyazawa, Biopolymers, 5, 673 (1967).
68. C. K. Johnson, ORTEP II, Report No. ONRL379Y, Oak Ridge National Laboratory, Oak Ridge, Tennessee, 1971.

69. P. J. Flory, "Statistical Mechanics of Chain Molecules", Wiley (Interscience), New York, N.Y., 1969.

70. W. H. Zachariasen, J. Am. Chem. Soc., 62, 10111013 (1940).

71. G. A. Jeffrey and G. S. Parry, J. Am. Chem. Soc., 76, 5283-5286 (1954).

72. G. Capaccio, P. Giacomello, and E. Giglio, Acta Cryst., A27, 229-233 (1971). 